\title{
EL DERECHO A LA SALUD EN LA JURISPRUDENCIA CONSTITUCIONAL COLOMBIANA*
}

\author{
RODOLFO ARANGO**
}

\begin{abstract}
RESUMO: O presente artigo visa apresentar um quadro do estado do direito da saúde na Colômbia sob uma perspectiva evolutiva, descritiva e analítica. O intuito é fornecer informação objetiva e suficiente em face de possíveis reformas dos mecanismos de proteção constitucional dos direitos ou do alcance das competências dos órgãos encarregados de sua defesa. A conclusão é que a ação de tutela é importante para a proteção do direito à saúde, especialmente em relação aos setores mais pobres da população. É mostrado também que é equivocada a idéia de que a jurisdição constitucional nessa matéria atenta contra a estabilidade do sistema de seguridade social em saúde.

PALAVRAS-CHAVE: Direito à saúde. Controle Judicial. Corte Constitucional.
\end{abstract}

ABSTRACT: This article intends to present a framework of the current state of the right to health in Colombia from an evolutionary, descriptive and analytical perspective. The aim is to provide objective and sufficient information in light of possible reforms of the constitutional-protection-of-rights mechanisms and of the authority reach of the entities charged with its defense. The conclusion is that the writ is relevant for the protection of the right to health, especially when underprivileged sections of the population are concerned. It is also proved wrong the idea that constitutional jurisdiction on this matter is hurtful to the health social security system's stability. KEYWORDS: Right to health. Judicial review. Constitutional Court.

SUMÁRIO: I. Introdução: contexto fático e normativo; II. Âmbitos e funções da intervenção constitucional na saúde; III. Contextos empíricos e notas de direito comparado; IV. Conclusões; V. Bibliografia.

SUMMARY: I. Introduction: factual and normative context; II. Scopes and functions of the constitutional intervention on health; III. Empirical contexts and compared law notes; IV. Conclusions; V. Bibliography.

SUMARIO: I. Introducción: Contexto Fáctico y Normativo; II. Ámbitos y Funciones de la Intervención Constitucional en Salud; III. Contextos Empírico y Notas de Derecho Comparado; IV. Conclusiones; V. Bibliografia.

\footnotetext{
* El presente artículo es una versión recortada de la investigación realizada gracias al apoyo de la Fundación Ford y la Universidad Externado de Colombia, Bogotá (mayo 2004).

** Profesor asociado, Departamento de Filosofía, Universidad de los Andes (Bogotá).
} 


\section{INTRODUCCIÓN: CONTEXTO FÁCTICO Y NORMATIVO}

En el año 2001, el cubrimiento de población asegurada en materia de seguridad social en salud era entre el 53\% al 57\% de la población colombiana (Restrepo 2002, 26-27; Arrieta 2002, 14-15), siendo significativo el avance con respecto al cubrimiento de menos del $20 \%$ en 1994, pero aún muy rezagado con respecto a la meta del $100 \%$ fijada por el Constituyente de 1991 y establecida para fines del año 2000 por la Ley 100 de $1993^{1}$. Las cifras correspondientes al año 2001 no habían variado hasta 2004: con una población cercana a los 44 millones y medio de habitantes según proyecciones del DANE ${ }^{2}$, entre el 43 al $47 \%$ de la población, o sea, entre 19 y 21 millones de colombianos, no tienen asegurado todavía su acceso al servicio público de seguridad social en salud.

El Constituyente de 1991 quiso enfrentar la situación de exclusión social, entre otras, mediante la reforma a la seguridad social. Es así como a partir de la Constitución de 1991 el régimen de la seguridad social en salud se sitúa en medio de dos tendencias. Por una parte, la realización del Estado social de derecho fundado, entre otros principios, en la dignidad humana y la solidaridad social. ${ }^{3}$ Tal principio de organización política tiene uno de sus desarrollos en el servicio público obligatorio de la seguridad social, el cual se presta bajo la dirección, coordinación y control del Estado, en sujeción a los principios de eficiencia, universalidad y solidaridad. ${ }^{4}$ En este marco, se inscribe el derecho de todos a acceder al servicio público de seguridad social en salud. ${ }^{5}$ La segunda tendencia se refiere a la liberalización y privatización de la prestación del servicio público de la salud, ${ }^{6}$ lo cual supone un nuevo acuerdo político y social de cooperación entre el sector público y el privado para alcanzar las metas fijadas por el propio constituyente cuando estableció que se "garantiza a todos los habitantes el derecho irrenunciable a la seguridad social" participación de los particulares, ampliará progresivamente la cobertura de la Seguridad Social que comprenderá la prestación de los servicios en la forma que determine la Ley." ${ }^{\circ}$ La anterior normatividad prefigura las tensiones entre los planos constitucional y legal en cuanto a las prestaciones inmediatamente exigibles que se desprenden de la garantía del derecho a la salud en contraste con la ampliación progresiva y la prestación del servicio en los términos de Ley.

En este contexto fáctico y normativo se plantea la presente investigación sobre el derecho a la salud en la jurisprudencia constitucional. Su propósito principal es el de describir y analizar la evolución de las decisiones de la Corte Constitucional en la materia, de forma que se disponga de información objetiva y suficiente de cara a posibles reformas de los mecanismos de protección constitucional de los derechos o del alcance

${ }^{1}$ Ley 100 de 1993, artículo 157 B inciso 2.

${ }^{2}$ Ello puesto que la última encuesta de población se realizó en 1993. Al respecto es posible consultar en: www.dane.gov.co/inf_est/censo_demografia.htm (Censos y demografía).

${ }^{3}$ Constitución Política, artículo 1.

${ }^{4}$ Constitución Política, artículos 48.

${ }^{5}$ Constitución Política, artículos 49.

${ }^{6}$ Constitución Política, artículos 48, inciso 4; y 49, inciso 2, segunda oración.

${ }^{7}$ Constitución Política, artículos 48, inciso 2.

${ }^{8}$ Constitución Política, artículos 48, inciso 3. 
de las competencias de los organismos encargados de su defensa. Para tal fin, la investigación distingue entre ámbitos de intervención y funciones de la intervención.

La metodología utilizada para describir y analizar la evolución de las decisiones de la Corte Constitucional aborda diversos ámbitos desde tres enfoques: a. los hitos de la jurisprudencia, que incluyen su tendencia básica y sus excepciones; b. algunos ejemplos ilustrativos con la descripción de los casos paradigmáticos; c. el análisis de los criterios empleados por la Corte para adoptar su decisión. ${ }^{9}$ De esta forma se busca cumplir con el propósito de la investigación consistente en presentar un cuadro del estado del derecho a la salud desde una perspectiva evolutiva, descriptiva y analítica. La investigación incluye luego tres apartados sobre la estadística de la jurisprudencia constitucional en salud; al alcance de los cambios propuestos por algunos de los proyectos de reforma constitucional sobre el tema; y, al tratamiento del derecho a la salud en el derecho comparado. El escrito concluye con un resumen ejecutivo a manera de conclusiones.

Es de advertir que para la presente investigación se ha basado en gran parte en tres excelentes trabajos que de sistematización y análisis de la jurisprudencia constitucional en materia de salud. Me refiero, por una parte, al documento DESC de la Defensoría del Pueblo, cuyo autor es el joven investigador Oscar Parra Vera, y titulado "El derecho a la salud en la Constitución, la jurisprudencia y los instrumentos internacionales” (Defensoría 2002). El segundo es el escrito de Mónica Arbeláez Rudas "La protección del derecho a la salud en sede de tutela” (Arbeláez 2000). El tercero es un estudio realizado por Aquiles Arrieta con título “Comentarios a la creación de jurisprudencia constitucional. El caso del acceso a los servicios de salud” (Arrieta 2002). Por último, quiero agradecer aquí a mi asistente de investigación Paula Torres Holguín por el apoyo brindado, así como por su dedicación y paciencia.

\section{II. ÁMBITOS Y FUNCIONES DE LA INTERVENCIÓN CONSTITUCIONAL EN SALUD}

Los ámbitos en que ha intervenido la justicia constitucional en relación con el derecho a la salud a los que nos referiremos abarcan: 1. la definición del derecho; 2. los beneficiarios del derecho; 3. los alcance del derecho (vg. de sus obligaciones correlativas); 4. el acceso al servicio; y, 5. la calidad al servicio de salud. En todos los mencionados temas la Corte Constitucional ha cumplido diversas funciones; entre ellas, las funciones: (i) definitoria del derecho fundamental a la salud y sus obligaciones correlativas; (ii) de protección especial a personas o grupos en situación de marginación o discriminación; (iii) de delimitación y coordinación de los niveles constitucional y legal; (iv) de control constitucional de la formulación y ejecución de las políticas públicas

\footnotetext{
${ }^{9}$ La función asumida por la Corte en los diferentes ámbitos se especificará al relacionar los criterios decisorios en cada caso. Ello porque el criterio empleado refleja o hace evidente la función que la justicia constitucional ha cumplido al adoptar la decisión. Así, por ejemplo, si se tutela a un niño su derecho a una prestación médica no contemplada en el Plan Obligatorio de Salud pero que requiere con urgencia, y ello se hace con apoyo en el criterio de que el derecho a la salud es, en el caso de los menores de edad, un derecho fundamental, entonces la Corte ha ejercido una función definitoria del derecho fundamental a la salud, así como una función protectora de un grupo de personas que gozan de protección especial y una función de delimitación de los planos constitucional y legal.
} 
en cuanto puedan afectar derechos fundamentales; (v) de integración e inclusión social mediante el respeto a los principios, derecho y deberes constitucionales.

\section{La definición del derecho}

El derecho a la salud ha sido interpretado, por regla general en la jurisprudencia constitucional, como un derecho fundamental por conexidad, con la excepción expresa del derecho fundamental a la salud reconocido expresamente a los niños por artículo 44 de la Constitución. No obstante, la Corte, en casos aislados, ha reconocido carácter fundamental al derecho a la salud para grupos de población especialmente protegidos o cuando se trata de proteger el núcleo esencial del derecho a la salud (Defensoría 2002, 41).

\section{a. Hitos, tendencia básica y excepciones}

Desde un principio, la jurisprudencia constitucional ha reconocido el doble carácter del derecho a la salud, una vez como fundamental y otra como derecho constitucional de orden social. En sentencia T-484 de 1992, la Corte expresa este doble carácter, en ocasiones sólo discernible en el caso concreto. ${ }^{10}$ Tal tesis tiene asidero en la doctrina constitucional que distingue entre los derechos fundamentales como derechos subjetivos directamente exigibles por sus titulares, y los llamados derechos sociales, económicos y culturales, que requerirían para su exigibilidad de desarrollo legal previo. No obstante, la jurisprudencia constitucional ha sostenido de manera continua y consistente que derechos del segundo grupo exhiben en ocasiones el carácter de fundamentales, en especial mediante la tesis de la conexidad inescindible entre el derecho social, en este caso la salud, y otros derechos en sí mismos fundamentales, como, por ejemplo, el derecho a la vida, en el sentido de que la prestación del servicio de salud es condición sine qua non para la protección adecuada de este derecho. En sentencia T-533 de 1992 la Corte muestra cómo en el caso concreto de un indigente que requería una intervención quirúrgica para no quedar ciego, el derecho a la salud adquiere el carácter de fundamental, puesto que las consecuencias de manera inmediata se revelan como un estado de cosas contrario a lo querido por el orden constitucional, que protege la vida y la integridad física de las personas. ${ }^{11}$

\footnotetext{
${ }^{10}$ En sentencia T-484 de 1992 sostuvo la Corte: "El derecho a la salud conforma, en su naturaleza jurídica, un conjunto de elementos que pueden agruparse en dos grandes bloques: el primero, que lo identifica como un predicado inmediato del derecho a la vida, de manera que atentar contra la salud de las personas equivale a atentar contra su propia vida. Por estos aspectos, el derecho a la salud resulta un derecho fundamental. El segundo bloque de elementos, sitúa el derecho a la salud con un carácter asistencial, ubicado en las referencias funcionales del denominado Estado Social de Derecho, en razón de que su reconocimiento impone acciones concretas. La frontera entre el derecho a la salud como fundamental y como asistencial es imprecisa y sobre todo cambiante, según las circunstancias de cada caso, pero en principio, puede afirmarse que el derecho a la salud es fundamental cuando está relacionado con la protección a la vida. Los derechos fundamentales, solo conservan esta naturaleza, en su manifestación primaria, y pueden ser objeto allí del control de tutela”.

${ }^{11}$ En sentencia T-533 de 1992, la Corte sentó el siguiente precedente: “““Acreditado el carácter de indigente absoluto - (i) incapacidad absoluta de la persona de valerse por sus propios medios; (ii) existencia de una necesidad vital cuya no satisfacción lesiona la dignidad humana en sumo grado; (iii) ausencia material de apoyo familiar - cabe reconocer en cabeza del sujeto y a cargo de la entidad pública respectiva, el derecho a recibir la prestación correspondiente, estableciendo - a la luz de las circunstancias - las cargas retributivas a su cargo (...)”.
} 
La regla general del derecho a la salud como derecho fundamental por conexidad se plasmó poco después de manera clara y explícita en sentencia T-571 de $1992 .{ }^{12}$ Variaciones jurisprudenciales se han presentado en relación con el objeto de la conexidad. Mientras que en la sentencia T-406 de 1992 el carácter fundamental del derecho a la salud puede darse, o bien en relación con otros derechos fundamentales o con principios fundamentales (Arbeláez 2000), a partir de la sentencia SU-111 de 1997 se ha sedimentado la regla según la cual dicha conexidad se refiere a únicamente derechos fundamentales. Una clara excepción a esta regla general la constituye el derecho fundamental explícito de los niños a la salud, como lo muestra la sentencia SU-225 de 1998.

La discusión de la jurisprudencia constitucional se ha centrado en el alcance de la conexidad, esto es, en la determinación de cuáles son los derechos fundamentales respecto de los cuales cabe reconocer la conexidad del derecho a la salud, y en consecuencia se tutela como derecho fundamental (Arrieta 2002, 11). Mientras que en la sentencia T-484 de 1992 la conexidad sólo abarca el derecho a la vida, en la T-499 de 1992 se extiende a la vida digna, ${ }^{13}$ la integridad y el libre desarrollo de la personalidad. Pero tal variación se ha decantado básicamente en la doctrina del derecho fundamental al mínimo vital, ${ }^{14}$ formula ésta que resume todos los derechos fundamentales en cuya conexidad el derecho a la salud adquiere el carácter de fundamental (Arango/Lemaitre 2002). Por derecho fundamental al mínimo vital la Corte ha entendido la posición jurídico constitucional que asegura el mínimo material necesario para garantizar las condiciones de una subsistencia acorde con la dignidad humana (T-426 de 1992, T-202 de 1995, T-011 de 1998, SU-225 de 1998, entre otras).

\section{b. Casos paradigmáticos}

Un caso ilustrativo de la protección constitucional del derecho a la salud reconocido como fundamental por su conexidad con los derechos a la vida digna, a la integridad personal y a la autonomía o libre desarrollo de la personalidad lo constituye la sentencia T-499 de 1992. Se trataba de una mujer que sufría de una

\footnotetext{
12 En sentencia T-571 de 1992, dejo la Corte en claro qué entiende por derecho fundamental por conexidad: "Los derechos fundamentales por conexidad son aquellos que no siendo denominados como tales en el texto constitucional, sin embargo, les es comunicada esta calificación en virtud de la íntima e inescindible relación con otros derechos fundamentales, de forma que si no fueron protegidos en forma inmediata los primeros se ocasionaría la vulneración o amenaza de los segundos. Es el caso de la salud, que no siendo en principio derecho fundamental, adquiere esta categoría cuando la desatención del enfermo amenaza con poner en peligro su derecho a la vida.”

${ }^{13}$ La Corte Constitucional ha sostenido reiteradamente que no solamente cuando la persona está al borde de la muerte se amenaza su derecho a la vida, sino que este derecho se ve igualmente amenazado cuando su titular es sometido a una existencia indigna, indeseable o dolorosa (Sentencias T-027 de 1999, T-344 de 1999 y T-457 de 2001).

${ }^{14}$ Ver, entre otras, la sentencia de unificación SU-225 de 1998 de la Corte Constitucional que al respecto sostiene: "Excepcionalmente (la Corte) ha considerado que los derechos económicos, sociales y culturales, tienen conexidad con pretensiones amparables a través de la acción de tutela. Ello se presenta cuando se comprueba un atentado grave contra la dignidad humana de personas pertenecientes a sectores vulnerables de la población y el Estado, pudiéndolo hacer, ha dejado de concurrir a prestar el apoyo material mínimo sin el cual la persona indefensa sucumbe ante su propia impotencia. En estas situaciones, comprendidas bajo el concepto del mínimo vital, la abstención o la negligencia del Estado se ha identificado como la causante de una lesión directa a los derechos fundamentales que amerita la puesta en acción de las garantías constitucionales”.
} 
lesión en la columna vertebral y quien debía ser intervenida quirúrgicamente. Ante la tardanza en la prestación del servicio y el dolor que le impedía, incluso, subir y bajar escaleras, interpuso acción de tutela con el objeto de que se ordenara la operación. $\mathrm{Al}$ revisar el caso, la Corte Constituciona ${ }^{15}$ precisó que cuando una entidad se niega a prestar un servicio que requiere una persona para detener, o al menos mitigar, los dolores y sufrimientos que le produce una enfermedad, somete la persona a tratos crueles e inhumanos (Defensoría 2002, 337). Con esta sentencia se inicia una línea jurisprudencial de protección constitucional al derecho a la salud como fundamental por su conexidad con la vida digna y la integridad personal. Según la Corte: "Una lesión que ocasiona dolor a la persona y que puede ser conjurada mediante una intervención quirúrgica, se constituye en una forma de trato cruel (CP art. 12) cuando, verificada su existencia, se omite el tratamiento para su curación. El dolor intenso reduce las capacidades de la persona, impide su libre desarrollo y afecta su integridad física y psíquica. La autoridad competente que se niega, sin justificación suficiente, a tomar las medidas necesarias para evitarlo, omite sus deberes, desconoce el principio de la dignidad humana y vulnera los derechos a la salud y la integridad física, psíquica y moral de la persona. (...) El dolor envilece a la persona que lo sufre. Si quien está en el deber de impedirlo no lo hace, incurre con su omisión en la vulneración del derecho a la integridad personal del afectado, quedándole a éste último la posibilidad de ejercer las acciones judiciales para la protección inmediata de sus derechos fundamentales”"16.

La sentencia SU-043 de 1995 resume la doctrina prevaleciente sobre el carácter fundamental del derecho a la salud en el caso de los niños. Se trataba de un menor que padecía de esclerosis tuberosa y de una enfermedad incurable, a quien le fuera suspendido el tratamiento médico por el Instituto de Seguros Sociales con base en la aplicación del artículo 26 del decreto 770 de 1975. En esta ocasión la Corte tuteló los derechos del menor, inaplicó la normatividad infraconstitucional y ordenó a la entidad demanda la reanudación del tratamiento médico, dejando en claro que "los derechos a la salud y a la seguridad social de los niños son derechos constitucionales fundamentales que deben tutelarse, como una obligación del Estado, de conformidad

\footnotetext{
${ }^{15}$ Sentencia T-499 de 1992. La Corte ordenó a la EPS que en el término de cuarenta y ocho (48) horas, ordenara llevar a cabo la totalidad de los exámenes médicos necesarios con el fin de determinar si la accionante requería ser intervenida quirúrgicamente y, en caso afirmativo, autorizar de manera inmediata la operación.

${ }^{16}$ Este precedente ha sido reiterado en diversas sentencias que enlista la Defensoría del Pueblo (2002, 377-8), así: sentencia T-322 de 1997 (cirugía de reemplazos articulares en ambas rodillas para enfrentar una artritis aguda), T-796 de 1998 (suministro de prótesis ocular para un menor de edad), T-572 de 1999 (suministro de prótesis mamarias en situaciones donde se afecta la integridad física y psíquica), T-1253 de 2000 (cirugía de reconstrucción del tendón de Aquiles que requería una persona con limitación y dificultad para caminar), T-1255 de 2000 (transplante de cornea requerido con urgencia), T-1384 de 2000 (cirugía para el tratamiento de una hernia discal), T-1742 de 2000 (intervenciones e implantes de material de osteosíntesis como tratamiento para una malformación en una pierna), T-579 de 2000 (cirugía para enfrentar calcificaciones que generaban mucho dolor e impedimentos para mover el brazo), T-910 de 2000 (intervención quirúrgica para tratar una fractura facial), T-494 de 2001 (cirugía para resolver un cálculo de colesterol), T-536 de 2001 (cirugía para el tratamiento de cólicos que generaban calambres e imposibilidad de trabajar), T-791 de 2001 (cirugía de columna), T-676 de 2002, T-855 de 2002 (cirugía para tratar la incontinencia mixta que genera dolor inmenso, continuo uso de pañales, imposibilidad de transporte en vehículos debido al dolor, necesidad de un cojín ortopédico para sentarse y dificultades para permanecer de pie).
} 
con lo establecido en el artículo 44 de la Carta Política.” Tal doctrina se reiteró luego en la sentencia SU-225 de 1998 y constituye, en la actualidad, doctrina uniforme en la jurisprudencia de la Corte.

\section{c. Criterios decisorios}

En punto a la definición del derecho a la salud la Corte ha ejercido la función definitoria o de delimitación conceptual del derecho por vía de la formulación de tres criterios: el criterio de la conexidad, el subjetivo y el material. Según el primer criterio, se requiere para aceptar el carácter fundamental del derecho a la salud en un caso concreto que exista una conexión entre el derecho a la salud y otros derechos fundamentales como la vida, la integridad, la libertad o, en general, el derecho fundamental al mínimo vital. Por su parte, el criterio subjetivo puede ser de orden iuspositivo explícito, como en el caso de los menores de edad por voluntad del propio Constituyente, ${ }^{17}$ o de orden interpretativo, como cuando la Corte ha reconocido el derecho fundamental autónomo a personas o grupos especialmente protegidos, como es el caso de las personas con discapacidades ${ }^{18}$ o personas de la tercera edad, también denominados “adultos mayores”"19 (por ejemplo, T-1219 de 2003). Por último, respecto al criterio material, la Corte ha sostenido igualmente que la prestación de salud ya reconocida por la ley o Plan Obligatorio de Salud adquiere el carácter de derecho fundamental autónomo, de forma que el incumplimiento de la misma constituiría una posible vulneración del derecho fundamental a la salud. ${ }^{20}$

\section{Los Beneficiarios del Derecho}

En aplicación de los principios constitucionales de dignidad y solidaridad, ${ }^{21}$ así como de protección especial a grupos discriminados o marginados y a personas que se encuentran en situación de debilidad manifiesta, ${ }^{22}$ la Corte ha reconocido como beneficiarios del derecho fundamental a la salud a menores de edad, a personas con pronóstico no favorable de curación, a mujeres embarazadas o luego del parto, a las minorías étnicas, a los adultos mayores, a las personas con alguna discapacidad, a los enfermos de SIDA, a las personas privadas de la libertad, a las personas en situación de desplazamiento forzoso o a las personas en situación de indigencia.

a. Hitos, tendencia básica y excepciones

En el caso de los menores de edad, la jurisprudencia ha establecido, pese a la incertidumbre inicial, que no es constitucionalmente admisible denegar la prestación

\footnotetext{
${ }^{17}$ Constitución Política, artículo 44.

${ }^{18}$ Corte Constitucional, Sentencia T-850 de 2002. En esta ocasión, la Corte tuteló el derecho a la salud de una mujer de 19 años con problemas mentales y en estado de pobreza, la cual requería una prestación de salud frente a un posible embarazo.

${ }^{19}$ Corte Constitucional, Sentencia T-004 de 2002. La Corte en esta ocasión tuteló el derecho a la salud de un adulto mayor y ordenó que se le suministraran los audífonos que requería. En igual sentido ver las sentencias T-1081 de 2001 y T-111 de 2003.

${ }^{20}$ Ver entre otras las sentencias de la Corte Constitucional T-859 de 2003 y T-860 de 2003. En la primera se trataba de un caso de dos personas a quienes una entidad prestadora de salud les negaba un tratamiento de rodilla por presuntamente no estar incluido en el plan obligatorio de salud. La Corte no compartió tal criterio y ordenó la prestación.

${ }^{21}$ Constitución Política, artículo 1.

${ }^{22}$ Constitución Política, artículo 13.
} 
de salud a un menor de edad con el argumento de que existe un pronóstico no favorable de curación. En efecto, si bien en sentencia T-200 de 1993 la Corte Constitucional hizo respetar una norma (Decreto 770 de 1975) en tal sentido, y denegó la tutela a un menor a quién se le suspendió un tratamiento ante el pronóstico no favorable de curación, pronto cambio radicalmente de posición. A partir de una lectura amplia del concepto “curación”, en sentencia T-001 de 1995 adoptó la tesis según la cual ésta "no necesariamente implica erradicación total de los padecimientos, sino que involucra las posibilidades de mejoría para el paciente, así como los cuidados indispensables para impedir que su salud se deteriore o disminuya de manera ostensible, afectando su calidad de vida." Tal doctrina se reafirma luego en la sentencia de unificación SU-043 de $1995 .^{23}$ Esta doctrina se ha extendido, por ejemplo, a pequeños que sufren síndrome de Down y parálisis cerebral pese a su diagnóstico adverso ${ }^{24}$ al insistir vigorosamente en la atención médica integral, preferente y especializada que es exigible por parte de los enfermos con pronóstico no favorable de curación. Luego, en sentencia T-920 de 2000, la Corte extendió los beneficios de la prestación de salud a las actividades de instrucción y educación en el tratamiento de rehabilitación de menores con discapacidad. Es así como en sentencia T-225 de 2003 la Corte reconoció dentro del contenido del derecho a la salud del menor afectado de sordera las terapias necesarias para su integración a la sociedad. Es de observar que la jurisprudencia ha extendido estos beneficios no sólo a menores de edad sino también a mayores de edad en situación de discapacidad que, si bien su edad biológica los hace mayores, de acuerdo a los médicos tratantes su edad mental corresponde a la de un niño menor ${ }^{25}$ (Defensoría 2002, 188).

La tendencia básica de proteger el derecho a la salud para personas de especial protección y ampliar el círculo de beneficiarios de manera que se incluya a los que, de otra manera, estarían excluidos del goce efectivo de la prestación de salud, no supone la inexistencia de límites constitucionales al reconocimiento de tal derecho. La Corte Constitucional también se ha preocupado por fijar condiciones para acceder gratuitamente al servicio público en caso de imposibilidad de asumir los costos de la prestación. Por ejemplo, mediante sentencia T-421 de 2001 la Corte denegó el correspondiente amparo a una menor con problemas de crecimiento y que requería del suministro de hormonas para combatir dicha enfermedad. La Corte consideró que no aparecía demostrada la incapacidad económica de los padres de la menor y que la obligación de suministrarle medicamentos excluidos del plan obligatorio de salud recae en primer lugar sobre los padres.

\section{b. Casos paradigmáticos}

De los múltiples beneficiarios del derecho fundamental a la salud por conexidad es posible ilustrar, como casos paradigmáticos, los relacionados con personas víctimas

\footnotetext{
${ }^{23}$ En sentencia SU-043 de 1995 la Corte destacó que "existe concepto médico autorizado, según el cual no obstante ser incurable la dolencia de la menor, su afección es controlable, lo cual habilita para que se le dé tratamiento de soporte, mantenimiento y control para evitar el deterioro de su salud, desde luego indeseable y proscrito a la luz de la Constitución y de la ley”.

${ }^{24}$ En sentencia T-131 de 1995, la Corte menciona la declaratoria de nulidad por parte del Consejo de Estado de la expresión '...y que exista desde el principio pronóstico favorable de curación', contenida en el artículo 26 del decreto 770 de 1975.

${ }^{25}$ Sentencias T-920 de 2000 y T-197 de 2003.
} 
de desplazamiento forzoso, indígenas o personas privadas de la libertad, entre otras. El círculo de beneficiarios se ha determinado en cada caso según las condiciones en que se encuentran los titulares del derecho, vg. la situación de desarraigo y total despojo material, la diversidad cultural o la relación especial de subordinación y privación de la libertad.

En 1997, 128 familias de municipios de Chocó y Antioquia víctimas del desplazamiento por acción de paramilitares interpusieron, cuatro años después, acciones de tutela por violación de sus derechos fundamentales, entre ellos el derecho a la salud. A este respecto argumentaron que la atención en salud era pésima en el sitio de refugio, porque no se realizaban exámenes médicos de diagnóstico, no había tratamientos por especialista y, además, no se hacía entrega de medicamentos. Mediante sentencia T-098 de 2002 la Corte Constitucional ordenó al Director Nacional de la Red de Solidaridad Social, procurar la ubicación de los desplazados en el régimen subsidiado, sin perjuicio de exigirle al hospital de Quibdo que, desde la misma fecha de la sentencia, procediera a atender a los desplazados de manera eficiente, suministrándoles los medicamentos necesarios, para luego repetir contra el FOSYGA. En esta sentencia se reitera jurisprudencia anterior en cuanto al trato preferente a los desplazados y se ordena su atención incluso exceptuando la exigencia legal de estar inscrito en el Registro Único de Desplazados para acceder al servicio. En sentencia de unificación SU-1150 de 2000, tesis reiterada en sentencia T-1635 de 2000, la Corte fijó en cabeza del Jefe del Estado la responsabilidad por la asistencia a la población desplazada, luego de encontrar que sólo el 22,1\% de las personas desplazadas contaban con atención de salud y que, además, el 45\% de dicha población requería atención psicológica. En sentencia T-327 de 2001 la Corte consideró que la interpretación más favorable a la protección de los derechos humanos de los desplazados hace necesaria la aplicación de los Principios Rectores del Desplazamiento Interno como parte del cuerpo normativo supranacional que integra el bloque de constitucionalidad.

Otro caso paradigmático en relación con la determinación del grupo de beneficiarios del derecho a la salud lo constituyen los miembros de comunidades indígenas, precisamente por las diferencias que los caracterizan frente a los demás habitantes del país. A la luz del principio fundamental de respeto a la diversidad étnica y cultural, la Corte, mediante fallo de constitucionalidad C-088 de 2001, convalidó la norma legal que brinda especial protección de los indígenas al incluir el subsidio alimentario como elemento de la atención en salud. Igualmente en el mismo fallo invocó el principio de autonomía de los pueblos indígenas para decidir sobre sus propios asuntos, y dejó a salvo la regulación legal que permite a las comunidades indígenas constituir sus propias administradoras del régimen subsidiado en salud. Por último, en dicha sentencia la Corte no consideró que la exclusión de las comunidades indígenas del pago de cuotas moderadoras y copagos, violara el principio de solidaridad. Pero en cuanto a los indígenas con capacidad de pago incluidos en el régimen contributivo y no en el subsidiado, la Corte aclaró que sí están obligados a cancelar cuotas moderadoras y realizar copagos, pues "no puede considerarse que existan razones culturales que los eximan del deber general de asistir a la financiación del sistema”. 
Un tercer grupo paradigmático de beneficiarios delimitado jurisprudencialmente dada su especial condición de sujeción, y a las dramáticas condiciones prevalecientes en las cárceles el país es el de las personas privadas de libertad que, precisamente por tal condición, se encuentran en una situación desventajosa respecto del goce del derecho a la salud. Es por ello que la Corte declaró el estado de cosas inconstitucional en materia de salud y asistencia médica y suministro de medicamentos al personal recluido en las cárceles del país, y ordenó llevar a cabo los trámites administrativos, presupuestales y de contratación indispensables para constituir o convenir un sistema de seguridad social en salud, bajo la modalidad subsidiada, que cobije a la totalidad de los centros de reclusión del país, para detenidos y condenados. Así mismo, la Corte ha defendido de manera reiterada los intereses de este grupo, tutelando de manera individual el derecho a la salud de los presos, en el caso de demoras en la prestación del servicio, o de una dilación injustificada en el traslado del paciente por parte de la Institución Penitenciaria a un centro asistencial de salud (ver entre otras las sentencias T-153 de 1998, T-535 de 1998, T-606 de 1998, T-607 de 1998, T-530 de 1999, T-575 de 1999 y T-233 de 2001).

\section{c. Criterios decisorios}

En relación con los círculos de beneficiarios, los jueces constitucionales y, en particular, la Corte Constitucional, han tenido como criterios decisorios la aplicación de principios o derechos fundamentales para asegurar la protección especial a ciertos grupos de personas; controlar el cumplimiento de los preceptos constitucionales por parte de otras autoridades públicas; y garantizar el respeto de mínimos materiales o condiciones de acceso a toda la población, en especial la menos favorecida. En esta tarea la Corte cumple las siguientes tres funciones básicas: (i) actualiza la protección especial establecida por la Constitución en favor de diversas personas o grupos de personas que la requieren. Además de los casos paradigmáticos arriba mencionados, también ha protegido a madres solteras (T-1642 de 2000), mujeres embarazadas o madres después del parto en situación de desamparo o desempleo mediante el reconocimiento de un subsidio alimentario (T-106 de 1996, T-694 de 1996, T-662 de 1997, T-844 de 2002); a mayores adultos (T-004 de 2002) en situación de indigencia para ser incluidos en programas de atención médica integral (T-149 de 2002); a enfermos de Sida en una reiterada jurisprudencia (T-484 de 1992, T-505 de 1992, T-1119 de 2002) no sólo para asegurar la realización de exámenes médicos de carga viral (T-849 de 2001) sino para el suministro de antiretrovirales en la cantidad y periodicidad indispensable (T-271 de 1995, T-328 de 1998, T-376 de 2003, T-919 de 2003); o, a personas con discapacidades físicas o mentales que requieren, por ejemplo, de prestaciones corrientemente no clasificadas dentro de la esfera de protección del derecho a la salud como en el caso de la educación o capacitación espacial para asegurar su rehabilitación o su integración social (T-478 de 1995, T-556 de 1998, T-338 de 1999, SU-1167 de 2001); (ii) controla el diseño y la ejecución de políticas públicas, como ha sucedido en materia carcelaria con las sentencias de estados de cosas inconstitucionales en las cárceles del país o en materia de atención a población víctima del desplazamiento forzado; (iii) incluye o integra socialmente a enfermos de sida, mayores adultos, madres solteras, desplazados, personas con discapacidades, etc., buscando su protección frente a situaciones de marginación y discriminación. 


\section{Los Alcances del Derecho (vg. De sus Obligaciones Correlativas)}

La principal labor de la Corte Constitucional en salud ha sido determinar el alcance del derecho constitucional y las obligaciones correlativas mediante la diferenciación de las prestaciones de orden iusfundamental en contraste a las prestaciones legales. La tensión entre la vigencia inmediata del Estado social de derecho y los principios de dignidad humana y solidaridad social, por una parte, y el desarrollo legal progresivo de los derechos prestacionales y su prestación por particulares y entidades oficiales, por otra parte, se ve reflejada en la jurisprudencia constitucional en la materia. Es así como la Corte ha establecido los lineamientos constitucionales a tener en cuenta por las entidades del sector salud, así como por los usuarios del mismo, de manera que se respeten los principios constitucionales y se haga posible el cumplimiento de las metas de extender los beneficios del progreso a toda la población.

En desarrollo de los principios de eficacia, universalidad y solidaridad, y en ejercicio de su atribución constitucional de establecer los términos en los cuales debe prestarse el servicio de seguridad social en salud, el legislador expidió la Ley 100 de 1993, "por la cual se crea el sistema de seguridad social integral y se dictan otras disposiciones”. ${ }^{26}$ Para el cumplimiento de dicha meta, se diseñó el sistema general de seguridad social de salud (SGSSS) con dos regímenes de cubrimiento: el régimen contributivo y el subsidiado. El primero destinado a afiliados con capacidad de pago, entendiendo por tales los empleados y los trabajadores independientes, a cargo de los cuales está el pago mensual de aportes al sistema. Al segundo se encuentran afiliadas las personas sin capacidad de pago, y su vinculación al sistema es subsidiada por el propio sistema. ${ }^{27}$ Ahora bien, el legislador previó temporalmente que las personas sin capacidad de pago que no hubieran entrado al sistema en calidad de afiliadas o beneficiarias, se entendían incorporadas al mismo en calidad de "vinculadas", de forma que tuvieran acceso a la prestación de servicios médico asistenciales mediante los servicios ofrecidos por la red pública de hospitales. ${ }^{28}$ Para efectos del ingreso al régimen subsidiado de salud, el SGSSS ha establecido un Sistema de Identificación de Beneficiarios -SISBEN- con miras a identificar la población sin capacidad de pago y a clasificarla en niveles de los cuales depende el alcance de los beneficios del sistema y la proporción de la prestación a ser subsidiada. Igualmente, la ley establece, en desarrollo del mandato constitucional, un sistema mixto de entidades públicas y privadas: las Empresas Promotoras de Salud (EPS) para el régimen contributivo

${ }^{26}$ En esta ley se definen los alcances de la seguridad social integral como el conjunto de instituciones, normas y procedimientos, de que dispone la persona y la comunidad para gozar de una mejor calidad de vida, mediante el cumplimiento progresivo de los planes y programas que el Estado y la sociedad desarrollen para proporcionar la cobertura integral de las contingencias en salud y la capacidad económica de los habitantes del territorio nacional, con el fin de lograr el bienestar individual y la integración de la comunidad.

${ }^{27}$ La ley ordena que un porcentaje de los ingresos nacionales y de las entidades descentralizadas se destine a subsidiar la demanda en salud; igualmente, un porcentaje de los aportes realizados por los afiliados al régimen contributivo es trasladado como subsidio para el régimen subsidiado (Arbeláez 2000).

${ }^{28}$ La ley 100 de 1993 preveía que el régimen vinculado desaparecería a fines de 2000 cuándo se lograra la universalidad en el cubrimiento, debiendo quedar la población adscrita al sistema bien mediante el régimen contributivo o el subsidiado. No obstante, como ya se afirmó, al presente por lo menos el $47 \%$ de la población no está cubierto por ninguno de los dos regímenes y existe incertidumbre sobre la vigencia de la norma sobre régimen vinculado. 
y las Administradoras del Régimen Subsidiado (ARS) para el régimen subsidiado, ambas encargadas de la administración de los recursos del sistema de salud. Además, para la prestación del servicio la ley igualmente dispone las Instituciones Prestadoras de Salud (IPS) a la prestación de los servicios médico asistenciales.

En este contexto constitucional y legal, la jurisprudencia constitucional ha delimitado el alcance del derecho a la salud (o de sus obligaciones correlativas), bien sea asegurando la prestación más allá de las obligaciones legales establecidas por el régimen contributivo mediante el Plan Obligatorio de Salud (POS) que incluye las prestaciones a cargo de la entidad de salud y a favor del asegurado, cuando ello se impone desde el plano constitucional para evitar la vulneración de derechos fundamentales; o corrigiendo vacíos y errores del régimen subsidiado como es el caso en relación con el diseño y aplicación del SISBEN como por ejemplo la dilación en la entrega del carné que acredita la calidad de beneficiario (ver, entre otras, las sentencias T-561 de 2003, T-645 de 2003), en directa aplicación de los principios de igualdad de oportunidades y protección especial a personas en situación de debilidad manifiesta.

\section{a. Hitos, tendencia básica y excepciones}

La jurisprudencia de la Corte en torno al alcance del derecho a la salud ha consistido, en su mayor parte, en la determinación de las obligaciones principales y accesorias, incluidas o excluidas del Plan Obligatorio de Salud. Una línea jurisprudencial diferente y significativamente menor en número de sentencias es la relativa a los conflictos entre médico y paciente (T-401 de 94) o su familia y que involucran otro tipo de derechos fundamentales asociados a la prestación del derecho a la salud como el derecho a la autonomía, por ejemplo en casos de ambigüedad genital (T-477 de 1995, SU-337 de 1999) o el derecho a una muerte digna (C-239 de 1997), o la libertad de cultos, como la transfusión sanguínea en el caso de los testigos de Jehová (T-474 de 1996).

La intervención de la jurisdicción constitucional se ha centrado en exigir el cumplimiento de obligaciones directa o indirectamente derivadas del Plan Obligatorio de Salud, de manera que las entidades prestadoras, públicas o privadas, respeten los principios constitucionales, sin que la eficiencia y el lucro sean los móviles determinantes o exclusivos en la prestación del servicio. En esta tarea la Corte ha enfatizado el principio de integralidad con que debe suministrarse la atención y el tratamiento de salud al ordenar terapias físicas necesarias para la plena recuperación (T-179 de 2000, T-133 de 2001); el principio de la buena fe que debe guiar el cumplimiento del servicio, como por ejemplo al limitar la excepción de no cumplimiento del contrato por no pago cuando la EPS se ha allanado a la mora mediante el recibo de la suma debida (T-059 de 1997); el principio de oportunidad de la prestación, según el cual la demora irrazonable en la atención médica o la dilación injustificada en la práctica de una operación constituyen violaciones de derechos fundamentales (T-046 de 1996, T-347 de 1996, T-260 de 1998, T-010 de 1999, T-344 de 2002); el principio de continuidad de la prestación, como cuando la Corte ordenó la continuación de un tratamiento de infertilidad ya iniciado por una EPS, pero luego abandonado por sus altos costos (T-572 de 2002), o a la continuidad del tratamiento a un enfermo de sida (T-411 de 2003). 
A la precisión de las obligaciones principales propias de la prestación del servicio se suma la clarificación respecto de obligaciones accesorias, derivadas del principio de confidencialidad, por ejemplo en el manejo de la historia clínica del paciente o el suministro de información sobre su estado (T-729 de 2002); del derecho a un consentimiento informado o cualificado, como sucede en el caso del cambio de sexo (T-477 de 1995); o del deber de control y vigilancia en cabeza del Estado, por ejemplo en materia de sanidad ambiental (T-380 de 1993, T-344 de 2002) o del control y vigilancia de la actividad privada en la prestación del servicio público de la salud (C-974 de 2002).

La tendencia básica de la jurisprudencia también abarca la delimitación de obligaciones que trascienden el marco del Plan Obligatorio de Salud y van más allá de lo expresamente prescrito por el POS mediante la aplicación preferente de los derechos fundamentales respecto del marco contractual y legal, principalmente para defender la vida, la dignidad y la integridad de la persona, mediante el reconocimiento del derecho fundamental a la salud por conexidad y su protección por vía constitucional para evitar su vulneración. Algunas de las prestaciones excluidas del POS y ordenadas por la Corte o los jueces constitucionales en desarrollo de los principios constitucionales son el suministro de prótesis para personas que han perdido alguno de sus miembros para buscar así su rehabilitación (T-941 de 2000); el suministro de pañales para mayores adultos con problemas de incontinencia (T-099 de 1999); el suministro de bolsas de colostomía (T-047 de 2003); el suministro de audífonos a personas de la tercera edad o con deficiencias del aparato auditivo (prestación inicialmente denegada en la jurisprudencia constitucional -T042 de 1999, T-1662 de 2000 o T-041 de 2001 - pero luego admitida en sentencia T-042 A de 2001, y reiterada, entre muchas otras, en las sentencias T-261, T-443 y T-506 de 2003); el suministro de hormona de crecimiento (T-666 de 1997, T-442 de 2000); el suministro de droga (viagra) contra la impotencia sexual en caso de afectación psicológica (T-926 de 1999, T-416 de 2001, T-004 de 2002) o la realización de cirugías oculares (T-533 de 1992, T-472 de 1999, T-860 de 1999, T-121 de 2000, T-1081 de 2001, T-827 de 2002, T-1096 de 2002). En este campo la tendencia de la Corte es la de ordenar el tratamiento o suministro médico por parte de la EPS a la cual se encuentra afiliada la persona y, en muchos casos, reconocer a la entidad obligada a repetir contra el Estado, en particular contra el Fondo de Solidaridad y Garantías (FOSYGA), para el reembolso de los costos que por Constitución o ley no le corresponde asumir como obligación social a cargo de los particulares.

La Corte también ha limitado el alcance del derecho a la salud en su jurisprudencia, por lo menos en lo que hace al contenido prestacional no exigible por vía constitucional. En efecto, ha sostenido que es la familia del enfermo y no las EPS la obligada al cuidado de personas con afecciones psicológicas cuando el nivel de agresividad del paciente ha disminuido hasta el punto de ser posible su tratamiento ambulatorio (T-209 de 1999). Por otra parte, la Corte ha convalidado la negativa de una EPS a remitir a su afiliado para ser atendido mediante medicina alternativa, cuando no está demostrada la eficacia de un tratamiento o medicamento por parte de las instancias de control respectivas (T-076 de 1999). Igualmente, la jurisprudencia 
constitucional ha denegado las tutelas del derecho a la salud cuando se pretende obligar a las EPS la realización de cirugías estéticas, salvo que se trate de intervenciones tendientes a mitigar el dolor (T-119 de 2000) o evitar implicaciones serias para la salud, como en el caso de la obesidad (T-171 de 2003).

\section{b. Casos paradigmáticos}

Representativos de la jurisprudencia relativa al alcance de los derechos y las obligaciones iusfundamentales en salud son los casos en los cuales la justicia constitucional fundamenta la orden de prestación del servicio por parte de una EPS no obstante el hecho de no estar obligada legal o contractualmente a ello. En las condiciones concretas del caso, en particular en presencia de situaciones de urgencia que ponen en riesgo la persona, la Corte aplica el principio de solidaridad y los deberes sociales de los particulares para garantizar el goce del derecho fundamental de la salud por conexidad.

Dos casos sirven para ilustrar el punto enunciado. El primero concierne a una mujer que presentaba un sangrado en sus oídos y que luego de esperar 6 meses a la cita con un especialista, pasados diecisiete meses no le habían realizado aun los exámenes ordenados por el especialista (T-366 de 1999). El segundo se refiere a otra mujer beneficiaria del Seguro Social con diabetes a quien le fuera ordenado un examen oftalmológico pero que a la fecha de presentación de la acción de tutela no se le había practicado aún por la inexistencia de un contrato entre la entidad de seguridad social y una clínica especializada (T-367 de 1999). En ambos casos la Corte consideró que el derecho a obtener un diagnóstico de la enfermedad, para lo cual se requiere la realización de los exámenes respectivos, hace parte del derecho fundamental a la salud en conexidad con la vida digna. A juicio de la Corte, cuando la vida y la salud de las personas se encuentren grave y directamente comprometidas por causa de operaciones no realizadas, tratamientos inacabados, diagnósticos dilatados, drogas no suministradas, con fundamento en razones económicas aun si están contempladas en normas legales o reglamentarias, pero que están supeditadas a la Constitución, cabe inaplicar dichas normas en el caso concreto en cuanto obstaculicen la protección solicitada (Defensoría 2002, 105).

En otras ocasiones la Corte ha antepuesto la protección constitucional de la vida y la integridad en conexidad con la salud al tutelar a mujeres que requerían intervenciones quirúrgicas urgentes (T-150 de 2000 y T-484 de 2000), pero que por razones de falta de cotización de las semanas mínimas exigidas por la ley o por la mora en el pago de los aportes a la salud, no eran ordenadas por parte de las entidades prestadoras con fundamento en la ley o el contrato (T-199, T-1053 y T-1173 de 2003). Para la Corte, si bien es cierto que las personas afiliadas tienen la obligación de realizar el pago cumplido de los aportes en salud, la entidad prestadora no puede, pese al no pago, invocar su derecho al no cumplimiento cuando está en peligro la vida del afiliado. En tal evento está ordenada constitucionalmente la ejecución de la intervención, sin desmedro del derecho de la entidad a exigir posteriormente del beneficiario la cancelación de lo debido.

Un caso en el cual la Corte se ha esmerado en avanzar en la construcción doctrinal de una dogmática de derechos fundamentales y de su vulneración, es el decidido en 
T-1279 de 2001. En esta ocasión, el padre de un menor que sufría de una "rinitis alérgica leve persistente" interpuso una acción para obligar a la EPS a la que estaba afiliado costear la práctica de un examen de alergias. En esta oportunidad, la Corte procedió a delimitar el alcance del derecho fundamental a la salud de un menor de edad y dejó en claro que, tratándose de un padecimiento que no compromete la vida digna o la integridad del menor sino que sólo le genera molestias, no se presenta una vulneración del derecho fundamental cuando la entidad prestadora se niega a practicar exámenes excluidos del plan obligatorio de salud. En este caso, la Corte sostuvo en relación con el alcance del derecho y las obligaciones correlativas: "El test de alergias no está contemplado por el P.O.S., es decir, no está comprendido dentro del alcance del derecho a la salud protegido por el legislador. Adicionalmente, como se indicó, dejar de practicar el examen en el caso concreto tampoco pone en riesgo derecho fundamental alguno, lo cual implica que en este evento no está constitucionalmente ordenado aumentar el ámbito de protección del derecho, amparado mediante tutela.”

\section{c. Criterios decisorios}

En el ámbito de la determinación del alcance del derecho a la salud, la Corte ha aplicado básicamente criterios que le permiten distinguir entre el plano constitucional y el plano legal. En este punto vuelven a ser importantes los criterios tenidos en cuenta por la Corte para definir el carácter fundamental del derecho, en la medida que de ello depende la protección por la justicia constitucional; pero a tales criterios se vienen a sumar los principios de razonabilidad y proporcionalidad, ya que la efectiva protección del derecho no sólo depende de su fundamentalidad sino de la vulneración o amenaza del mismo, por ejemplo, como consecuencia del incumplimiento de las obligaciones correlativas. En este terreno la Corte cumple entonces esencialmente cuatro funciones: (i) ejerce el control constitucional de delimitación y coordinación de los niveles constitucional y legal, en particular al impedir que la ejecución de los contratos de salud se lleve a cabo en desmedro de los derechos fundamentales; en este punto es crucial entender que el contrato de salud no es un simple contrato privado, en el que la autonomía de la voluntad privada sea el factor determinante, sino que tiene además un carácter público debido a su objeto, razón por la cual el Estado se ve llamado a intervenir en la libertad de un ámbito tradicionalmente privado. (ii) intermedia en la distribución y asignación de cargas públicas mediante la exigibilidad de obligaciones principales y accesorias en materia de salud; (iii) sirve de árbitro de conflictos que pueden presentarse entre paciente y/o familia, y entidad prestadora de salud; (iv) ejerce una función pedagógica, cuando enfatiza que el sistema de salud depende de la cooperación de afiliados, entidades prestadoras y Estado, así como de la coordinación de múltiples niveles de obligaciones, en todo lo cual los abusos de las partes -de los usuarios al exigir más de lo que la sociedad está obligada a reconocerles, y las entidades prestadoras al negar lo que constitucionalmente están obligadas a reconocer en forma oportuna e integral- deben evitarse, como también la visión que evalúa el sistema de salud sólo en términos económicos.

\section{El Acceso al Servicio de Salud}

a. Hitos, tendencia básica y excepciones

El acceso al servicio de salud es un asunto que concierne tanto a los afiliados al 
sistema, bien sea mediante el régimen contributivo o subsidiado, como al $47 \%$ de la población que aún no se encuentra incluida en el sistema general de seguridad social en salud. Ya nos hemos referido indirectamente al acceso al servicio por parte de los contribuyentes cuando abordamos el tema del alcance del derecho, por ejemplo en relación con las prestaciones excluidas del POS. Es importante entonces referirse ahora a la tarea que han cumplido los jueces constitucionales en relación con el acceso al servicio de la población subsidiada o de la población aún no cubierta por el sistema.

El problema de acceso al servicio por parte de personas afiliadas al régimen contributivo o al subsidiado tiene que ver con el goce efectivo del derecho. Dicho acceso se ve afectado, entre otras causas, por dilaciones injustificadas. La Corte ha garantizado una y otra vez el acceso al servicio al reconocer vulneraciones al derecho a la salud por la no prestación oportuna de las prestaciones debidas (T-042, 281, 347 de 1996, T-688 de 1998, T-010 de 1999, T-190, 227, 229 y 539 de 2000). Resultado de la reiterada jurisprudencia en la materia es lo que la misma Corte ha venido en llamar las "hipótesis fácticas mínimas” para evaluar la razonabilidad del plazo que se toma una entidad prestadora para garantizar el acceso efectivo al servicio de salud. En la sentencia T-889 de 2001 de la Corte Constitucional estableció que "para la prestación oportuna de un servicio médico, no es razonable el plazo que es indeterminado o cuya determinación es librada a decisiones eventuales dentro de un rango temporal muy amplio cuando (i.) la gravedad de la enfermedad requiere un tratamiento urgente, (ii.) el tipo de procedimiento ordenado por los médicos, al diferirse en el tiempo, pierde efectividad para aliviar el dolor o evitar la progresión fatal de la enfermedad, y (iii.) la entidad podría disponer de recursos para fijar en un lapso menor las características y la frecuencia del tratamiento requerido. Estos son los elementos fácticos mínimos cuya comprobación conduce a la concesión de la tutela que presente, (...) quien necesita y reclama una atención médica oportuna.”

Por su parte, los problemas de acceso al servicio por parte de personas pobres mediante el régimen subsidiado tienen que ver fundamentalmente con el diseño y la aplicación del Sistema de Selección de Beneficiarios de Programas Sociales $(\mathrm{SISBEN})^{29}$. Como bien lo ha diagnosticado la doctrina, la jurisprudencia y lo recoge ahora la Defensoría del Pueblo, el acceso a través del régimen subsidiado tiene como trasfondo el dilema propio de la distribución de bienes escasos. La situación de pobreza que vive Colombia hace que los recursos disponibles para la asistencia social sean insuficientes para atender a toda la población económicamente desfavorecida. Los principales problemas sobre los que la jurisprudencia se ha pronunciado en torno al régimen subsidiado, se concentran en las dificultades para realizar las entrevistas, las deficiencias en las mismas y el prolongado lapso de tiempo después de la entrevista sin que se haga efectivo el acceso (Defensoría 2002, 173-4). En algunos casos, se ha ordenado que los enfermos graves o algunos sujetos de especial protección sean vinculados inmediatamente al régimen subsidiado (T-436 de 2003). En otros eventos, se ha ordenado que el SISBEN agilice la encuesta y/o la inclusión

${ }^{29}$ El SISBEN es un conjunto de reglas, normas y procedimientos, que permiten obtener información socioeconómica de los sectores más vulnerables en las áreas rural y urbana a fin de clasificar a las personas según niveles de los cuales se hace depender el acceso a las diversas prestaciones. 
del afectado en la lista de candidatos que esperan su afiliación. En este campo la Corte ha reconocido diversos derechos y establecido algunas subreglas constitucionales, como lo recuerda la investigación de la Defensoría del Pueblo: El derecho al habeas data es vulnerado cuando la administración es negligente en la recolección de datos para la clasificación en el SISBEN (T-307 de 1999); las autoridades encargadas del SISBEN deben comunicar a los beneficiarios los cambios que se presentan en la clasificación en categorías y en la prestación de los servicios de salud (T-003 de 2000); ante situaciones de urgencia en las que está en riesgo la vida de las personas, deben agilizarse los trámites administrativos necesarios para acceder a los servicios médicos del régimen subsidiado de salud (T-723 de 2000); existe un derecho a la reclasificación en el SISBEN conforme a datos reales; el carné de afiliado al SISBEN no es el que otorga el derecho a la atención médica en casos donde se configura la situación de hecho generadora de derechos (T-961 de 2001); además, las situaciones de vulnerabilidad, como el estado de embarazo, y las circunstancias de debilidad manifiesta, deben ser tenidas en cuenta como elementos relevantes para focalizar los beneficios del régimen subsidiado (T-1083 de 2000).

En relación con la población del régimen vinculado que aún no accede al servicio de salud, la jurisprudencia de la Corte ha recalcado la obligación que tienen los Departamentos de asegurar el acceso al servicio de las personas que no se encuentran ni en el régimen contributivo ni en el subsidiado. ${ }^{30}$ Según la Corte en sentencia T-053 de 2002: "Una persona que requiera indispensablemente atención médica y el acceso a ella esté garantizado por una entidad territorial, tiene el derecho a: (i) recibir de ésta información sobre el servicio de salud, los beneficios con que cuenta y lo que debe hacer para recibir la atención que requiera; (ii) a que ésta le indique específicamente la institución encargada de prestarle el servicio y (iii) a que le acompañe en el proceso que culmine con la atención, de tal forma que se le garantice el goce efectivo de sus derechos constitucionales a la vida, a la integridad física y a acceder a los servicios de salud.”

\section{b. Casos paradigmáticos}

Algunos casos paradigmáticos de acceso al servicio de salud pueden ser mencionados para ilustrar la posición de la Corte Constitucional en este ámbito. El primero se refiere a la negativa de las entidades prestadoras de salud a atender a trabajadores respecto de los cuales el patrono está en mora de cancelar las cuotas correspondientes. En estas ocasiones la Corte ha observado que negar al trabajador el acceso al servicio de salud, bien sea a cargo del patrono o de la EPS, resulta inconstitucional, pues constituye una restricción desproporcionada de su derecho a la salud. La Corte ha sostenido también que la terminación del contrato laboral, no es

\footnotetext{
${ }^{30}$ Según el artículo 157 de la Ley 100, a partir del año 2000, todo colombiano deberá estar vinculado al Sistema a través de los regímenes contributivo o subsidiado. Además, progresivamente se unificarán los planes de salud para que todos los habitantes del territorio nacional reciban el POS. Por su parte el Acuerdo 77 de 1997 del Consejo Nacional de Seguridad en Salud establece que ""[l]as personas, sin capacidad de pago, que no hayan podido afiliarse al régimen subsidiado por disponibilidad de recursos para subsidios a la demanda, deberán ser atendidas, en calidad de vinculados, en las Instituciones Prestadoras de Servicios de Salud públicas o Empresas Sociales del Estado o IPS privadas que tengan contrato con el Estado para el efecto, con cargo a los recursos del subsidio a la oferta”.
} 
razón suficiente para que la entidad interrumpa la continuidad del servicio de salud (T-1079 de 2003). En sentencia de unificación SU-592 de 1999 la Corte deja en claro que patrono y EPS tienen una responsabilidad compartida a fin de proteger el derecho a la salud del trabajador. ${ }^{31}$

Un segundo caso se relaciona con las dificultades que enfrentan personas pertenecientes al régimen subsidiado como las que acceden al servicio en calidad de vinculadas. Una de tales dificultades tiene que ver bien con el diseño o la realización de la encuesta para acceder al sistema subsidiado. Una mujer soltera, embarazada y desempleada fue clasificada en nivel III del SISBEN, lo que la excluía del servicio gratuito de salud en caso de embarazo. La Corte tuteló su derecho fundamental de la salud y la de su hijo en conexidad con el derecho a la vida (T-1083 de 2000) y recogió la jurisprudencia sobre deberes del estado en la distribución de recursos escasos a la población pobre. A este respecto sostuvo la Corte en sentencia T-499 de 1995: "La realización del principio de igualdad en la asignación de recursos escasos consiste en garantizar, a los posibles beneficiarios, el acceso, en condiciones de igualdad, a los procedimientos por medio de los cuales las instituciones distribuyen esos recursos. Si bien la elección de los principios y procedimientos particulares de distribución que cada entidad establece - con base en la ley - forman parte de su autonomía operativa, éstos no pueden contrariar los parámetros que se derivan de los principios y valores constitucionales: todos los posibles beneficiarios deben tener iguales oportunidades de acceso; el procedimiento no puede favorecer a ningún grupo de beneficiarios en particular; los mecanismos de selección no pueden conducir a establecer discriminaciones contrarias a la Carta, etc. En este orden de ideas, por lo menos en las dos situaciones siguientes, es innegable la dimensión constitucional de la controversia: (1) cuando el procedimiento es constitucionalmente adecuado, pero alguna de sus etapas o requisitos se violan o pretermiten y esto determina que un beneficiario sea excluido del subsidio, al cual habría accedido si el procedimiento se hubiera cumplido a cabalidad; (2) el procedimiento se observa, no obstante su diseño contraría las normas constitucionales, por ejemplo, se descubre que los mecanismos aplicados implican una exclusión sistemática de personas caracterizadas por algún factor relacionado con la raza, el sexo o la edad."

\section{c. Criterios decisorios}

En materia de acceso al servicio de la salud, la jurisprudencia constitucional se encarga de, por una parte, incluir a los excluidos y, por otra, establecer reglas claras que permitan al legislador y a las instancias reguladoras atender a los parámetros constitucionales que enmarcan la prestación del servicio. Los criterios decisorios tienen en cuenta las circunstancias concretas de cada caso, con lo que se hace justicia a la situación particular de las personas, como sucede, por ejemplo, respecto de la

\footnotetext{
${ }^{31}$ Sostiene en esta oportunidad la Corte que las EPS cuentan con los instrumentos para cobrar los aportes y tienen el deber jurídico de administrar eficientemente los recursos. Existe pues una responsabilidad compartida entre la EPS y el patrono, por lo cual puede ser procedente que, en determinados casos, y según las particularidades de las diversas situaciones, los jueces de tutela ordenaran a uno o al otro el cumplimiento de las prestaciones de salud que eran necesarias para proteger un derecho fundamental. Ello refuerza a su vez la opción del trabajador para reclamar bien sea al empleador o a la EPS (Defensoría 2002, 118).
} 
formulación de la encuesta del SISBEN o su realización en la práctica. Tales criterios se ocupan igualmente de delimitar y coordinar los niveles constitucional, legal y administrativo, por ejemplo al dejar en claro que el acceso igualdad de oportunidades al servicio de la salud depende muchas veces de la base informacional y su equitativa difusión por parte de los órganos ejecutores. Parte entonces de la labor de la Corte Constitucional con respecto a la distribución de recursos escasos en calidad de subsidios a la población pobre para posibilitar el acceso a los servicios de seguridad social, ha sido detectar los problemas existentes ${ }^{32}$ y subrayar los deberes que tienen las autoridades con miras a asegurar la protección efectiva de los derechos de la población. Así, en sentencia T-149 de 2002 mencionó la Corte tres de dichos deberes: 1) el deber de precisar, mediante una definición clara, los elementos que constituyen el supuesto de hecho para reconocer una determinada prestación pública en cabeza de una persona; 2) el deber de acopiar información empírica suficiente para establecer si la persona que solicita la asistencia o protección cae bajo la hipótesis del supuesto de hecho que justifica asignarle una prestación; 3) el deber de evaluar el impacto que una decisión determinada - inclusión o exclusión de la persona a un programa - tiene sobre el cumplimiento presente y futuro de los objetivos del programa. ${ }^{33}$ En la sentencia T-683 de 2003, la Corte negó el tratamiento por fuera del POS a una persona que aducía la imposibilidad de trabajar por su dolencia y a quien, no obstante, se le demostró tener cinco cuentas bancarias activas, haciendo evidente su capacidad de sufragar el medicamento. En este caso, relativo a la distribución de recursos de asistencia social a mayores adultos en situación de pobreza, la Corte aplicó el criterio de la transparencia en el manejo de la información necesaria para acceder a los subsidios. En palabras del Alto Tribunal: "En el proceso de toma de decisiones administrativas deben observarse, por lo tanto, las exigencias mínimas que se desprenden del derecho al debido proceso frente a las actuaciones de la administración y los principios que rigen el ejercicio de la función pública, como la igualdad, la imparcialidad, la publicidad y la eficacia (artículo 209, inciso 1, C.P.). Con respecto a la transparencia y al manejo de la información - aspectos ambos relevantes en el presente proceso - no sobra resaltar lo importante que resulta su acatamiento. La transparencia del proceso decisorio no sólo facilita su inteligibilidad para el ciudadano, sino que promueve un trato digno y justo de la persona solicitante. Lo contrario es instaurar un proceso secreto e incontrolable en el que el ciudadano ignora la forma y las razones que llevan a la administración a una decisión con implicaciones vitales para el solicitante.”

\section{La Calidad al Servicio de Salud}

Un aspecto neurálgico del goce del derecho a la salud es el buen funcionamiento de su prestación por parte de las entidades públicas y privadas encargadas para ello.

\footnotetext{
${ }^{32}$ Según sentencia T-149 de 2002 tales problemas tienen que ver, entre otras cosas, con "la ambigüedad o la incoherencia de los fines del programa, la incertidumbre suscitada por una evidencia empírica insuficiente o la no sostenibilidad económica del programa amenazan con frustrar la debida prestación de la seguridad social y el cumplimiento de los deberes sociales del Estado respecto de los más necesitados.”

${ }^{33}$ Aquí, sin embargo, la relevancia de un análisis consecuencialista se limita a apreciar el impacto de la decisión sobre los derechos de la persona. Un análisis del impacto económico de la decisión es materia que corresponde tratar al ejecutivo y al legislativo al formular y aprobar la política pública respectiva.
} 
La calidad del servicio hace parte de dicho desempeño adecuado, puesto que las fallas y deficiencias del sistema de salud repercuten casi siempre en la lesión o amenaza de los derechos de los beneficiarios. Para el mantenimiento del nivel de calidad en la prestación del servicio público de la salud es indispensable el ejercicio permanente y oportuno del control y vigilancia por parte de los organismos del Estado que tienen dicha función. En este campo la jurisprudencia de la Corte Constitucional ha insistido en que la administración de la seguridad social debe ser “expresión del ejercicio racional y razonable de la función pública y de la justicia como característica primordial del orden social” (T-149 de 2002).

\section{a. Hitos, tendencia básica y excepciones}

La jurisprudencia constitucional, en sede tanto de constitucionalidad como de tutela, ha examinado diversos aspectos relacionados con la calidad del servicio público y fijado condiciones mínimas a satisfacer por parte de las entidades prestadoras. Se trata de una larga lista de sentencias que se inicia tempranamente y que ejemplifica la colaboración armónica entre las instancias judiciales, legislativa y ejecutiva en la realización del derecho a la salud mediante la organización, regulación, dirección, vigilancia y control del servicio.

Una de las primeras sentencias con incidencia sobre la calidad del servicio de la salud tiene que ver con el artículo 2 de la Ley 14 de 1962, que exige título profesional de médico y cirujano para poder ejercer la medicina y la cirugía. La norma fue demandada, entre otras razones, por vulnerar el derecho al trabajo de los llamados médicos "empíricos". Mediante sentencia C-377 de 1994 la Corte Constitucional declaró exequible la norma y precisó que si bien la Constitución garantiza la libertad de escoger profesión u oficio, también autoriza al legislador a exigir títulos de idoneidad, regular, vigilar y controlar el ejercicio de las profesiones $\mathrm{u}$ oficios que implican un riesgo social para la comunidad o los derechos de los demás, ${ }^{34}$ dejando a salvo la práctica de la medicina por parte de chamanes y curanderos dentro de la tradición cultural indígena. ${ }^{35}$ Tal doctrina viene a reiterarse en sentencia C-038 de 2003 donde la Corte encontró razonable la exigencia legal de un título de idoneidad adicional o de especialista para el ejercicio de la radiología e imágenes diagnósticas, con la finalidad de proteger la salud de los asociados en múltiples campos y en situaciones que muchas veces revisten gravedad, bien que sin duda alguna forma parte del interés general o público.

En ese mismo año la Corte inicia una línea jurisprudencial sobre la calidad del servicio mediante la tutela del derecho a la salud ante la negligencia científica o

\footnotetext{
${ }^{34}$ No obstante en esta ocasión, como posteriormente en sentencia C-226 de 1994 en relación con la profesión de bacteriólogo, la Corte precisó que “tales regulaciones sólo son legítimas constitucionalmente si se fundamentan de manera razonable en el control de un riesgo social, y no se traducen en una restricción desproporcionada o inequitativa del libre ejercicio de las actividades profesionales o laborales” (C-226 de 1994).

${ }^{35}$ Puntualizó la Corte en relación a la posibilidad legal de exigir títulos de idoneidad para ejercer la medicina: "Todo lo dicho no implica que en algunos grupos especiales, tales como las tribus indígenas, no puedan existir brujos, chamanes o curanderos que se dediquen a su oficio según sus prácticas ancestrales. Su actividad está protegida por el artículo 7o. de la Constitución, que asigna al Estado la obligación de reconocer y proteger la diversidad étnica y cultural.”
} 
administrativa de las entidades encargadas de su prestación. Para la Corte, la negligencia no puede constituir una justificación válida para negar la protección efectiva del derecho a la salud a los pacientes, menos todavía cuando se trata de menores (T-443 de 1994, T-705 de 1999, T-242 de 2000, T-387 de 2001, T-324 de 2003). Dicha negligencia puede consistir, por ejemplo, en la dilación prologada para brindar el servicio, la ausencia de procedimientos para evaluar la situación del paciente, la deficiente información para tomar decisiones, la suspensión del tratamiento o la medicación, etc. Posteriormente, mediante sentencia T-533 de 1996 la Corte amplió el espectro de conductas que atentan contra la calidad del servicio al estimar que se vulnera el derecho a la salud cuando una entidad prestadora cambia unilateralmente las condiciones o reglas del juego que rigen la relación con el afiliado, por ejemplo en lo que respecta a preexistencias no cubiertas por el seguro de salud. Tal doctrina se ha reiterado luego en sentencias SU-054 de 1998, SU-1554 de 2000 y T-549 de 2003.

Una contribución adicional a la promoción de la calidad de la salud lo constituye la concesión legal de estímulos e incentivos sin carácter salarial para los trabajadores y profesionales de la salud que trabajen en regiones alejadas de los centros urbanos. Al analizar la constitucionalidad de un artículo de la Ley 100 de 1993 la Corte precisó que el Gobierno Nacional puede contar con facultades extraordinarias para manejar dichos estímulos. Quizás una de las decisiones más importantes para la salvaguarda de la calidad de la salud es la sentencia C-1165 de 2000 mediante la cual la Corte declaró inconstitucionales algunas normas de la Ley 344 de 1996 en cuanto reducían la cotización de solidaridad del régimen contributivo. A juicio de la Corte medidas fiscales como las demandadas bien podrían tomarse si la cobertura de la seguridad social en salud ya hubiera abarcado la totalidad de la población colombiana o si se encontrara demostrado que la disminución de los recursos ocurre como consecuencia de haber disminuido el número de quienes necesitan acudir al régimen subsidiado por no poder cotizar al régimen contributivo. No obstante, no siendo ese el caso, la Corte invalidó dichas disposiciones y enfatizó que tal realidad es aun lejana, por lo que las normas que buscan la racionalización del gasto público no pueden desconocer la prioridad del gasto público social sobre cualquier otra asignación (art. 366 CP).

Por otra parte, la Corte ha reconocido el ámbito de libre configuración legislativa en relación con la organización del sistema de salud, todo ello dentro del marco de respeto a los principios fundamentales. En efecto, en sentencia C-616 de 2001 la Corte declaró exequible la decisión legislativa de permitir la prestación del servicio de salud por parte de las EPS por intermedio de instituciones prestadoras de salud propias, siempre y cuando no se genere una posición dominante en el mercado. ${ }^{36}$ Además, mediante sentencia C-1489 de 2000 la Corte encontró que el privilegio del subsidio a la demanda como la existencia de entidades con función de intermediación

\footnotetext{
${ }^{36}$ Sostuvo en esta oportunidad la Corte que no era contrario a la Constitución que el legislador, en ejercicio de su potestad de configuración legislativa, pretenda promover una prestación eficiente y oportuna del servicio mediante un modelo que diferencia funcionalmente entre la administración por parte de las EPS y la prestación de los servicios asistenciales por las IPS, pero que a la vez permite a las EPS prestar los servicios a través de sus propias IPS.
} 
para el desarrollo de la prestación de servicios de salud en el régimen subsidiado (ARS), se ajustan al margen de configuración legal del servicio público de salud establecido constitucionalmente, sin que ello implique la destinación de gastos a actividades diferentes de la prestación de servicios de salud.

Una excepción a la línea jurisprudencial anterior es la sentencia C-116 de 1999, mediante la cual la Corte declaró inexequible el artículo 57 de la Ley 23 de 1981, por la cual se dictan normas en materia de ética médica. Dicha norma había sido demandada por vulnerar la libertad de expresión y el derecho al trabajo de los médicos al restringir la posibilidad de dar a conocer sus servicios a través de medios diferentes a publicaciones de carácter científico. La Corte Constitucional consideró que si bien la práctica de la medicina debe estar sometida a altos niveles tanto técnicos como científicos de competitividad, seriedad, responsabilidad e idoneidad, la norma demandada al limitar la forma en que los profesionales de la medicina podían promocionar sus servicios restringía desproporcionadamente sus libertades y derechos fundamentales.

Finalmente no debe olvidarse que la calidad del servicio de la salud depende en gran parte de la calidad de los medicamentos. En sucesivas sentencias de tutela la Corte ha dejado en claro que son las acciones populares el mecanismo judicial procedente para la defensa del derecho colectivo a la calidad de los medicamentos (T-1451 de 2000 y SU-1116 de 2001, reiteradas en la sentencias T-966 de 2002). No obstante, en circunstancias de indefensión, urgencia y riesgo inminente para los derechos fundamentales, ha admitido la procedencia de la acción de tutela para evitar un perjuicio potencial inminente e irremediable (T-322 de 1994).

\section{b. Casos paradigmáticos}

La calidad del servicio de salud es un objetivo fundamental, tanto a nivel de la prestación del servicio mediante la atención básica a la población aun no incluida en el sistema de aseguramiento, como en materia del suministro de medicamentos o tratamientos idóneos, incluso por fuera del POS, para la recuperación de la salud. Ejemplo de lo primero lo constituyen las sentencias de tutela en las que la Corte ha tutelado el derecho a la salud frente a la práctica de entidades suministradoras de energía de suspender el suministro ante la mora en el pago del servicio por parte de clínicas y hospitales, entre otras entidades. En sentencias T-881 de 2002 y T-134 de 2003 la Corte recalca la importancia del principio de prestación continua del servicio de energía a los llamados bienes constitucionalmente protegidos como hospitales, cárceles o instalaciones de seguridad aérea o terrestre. A juicio de la Corte, la interrupción del servicio por parte de las entidades prestadoras, ante el no pago del servicio por parte de clínicas u hospitales, carece de justificación constitucional puesto que del correcto funcionamiento de estos centros depende directamente de dichos servicios.

Por su parte, la calidad del servicio de salud depende, en muchas ocasiones, de tratamientos y medicamentos excluidos del POS pero ordenados por el médico tratante. Por ejemplo, el médico tratante de una persona que sufría de "artritis reumatoide agresiva” consideró que la paciente necesitaba de un medicamento diferente a aquellos 
ya suministrados sin éxito, pero el cual no se encontraba incluido en el POS. Ante la negativa de la EPS a suministrar el medicamento con fundamento en que no se encontraba en el listado del POS y que el comité técnico científico había conceptuado que aun no se habían agotado todos los medicamentos posibles para tratar la enfermedad, la afectada interpuso una acción de tutela contra la entidad de salud. La Corte Constitucional al revisar el fallo de instancia reiteró ${ }^{37}$ la subregla constitucional según la cual prevalece el concepto de médico tratante incluso cuando el comité técnico científico de la entidad considera que el suministro de un medicamento no es necesario y que, además, existen otras posibilidades terapéuticas. La Corte considera que es el médico tratante es la persona más competente para determinar si un paciente realmente necesita un medicamento y con qué grado de urgencia. No obstante, la Corte equilibra la balanza a favor de la razonabilidad en el uso de los recursos del sistema de salud al permitir que las EPS pueden llegar a desatender las órdenes de los médicos tratantes cuando ellas son evidentemente inapropiadas, como cuando se ordena el suministro de un tratamiento o medicamento innecesario o inadecuado (T-1325 de 2001, T-223, T-644 y T-048 de 2003).

\section{c. Criterios decisorios}

El tema de la calidad del servicio de la salud, más que cualquier otro, ha dado lugar a la intervención de la Corte Constitucional en dos planos: la revisión constitucional de las decisiones legislativas que establecen el marco normativo general del sistema de salud y el examen constitucional de los actos de regulación por parte de las autoridades públicas que ejercen esta facultad, así como de las actuaciones de las entidades públicas y privadas encargadas de la prestación del servicio. En ambos planos la Corte ha aplicado criterios decisorios en los que se reconoce un amplio margen de configuración legislativa al Congreso en la materia según lo querido por el Constituyente y plasmado en los artículos 48 y 49 de la Constitución. Pero nuevamente la jurisprudencia constitucional se apoya en los criterios de razonabilidad y proporcionalidad al definir los contornos de las competencias legales y administrativas del Estado regulador. Es aquí donde surge con mayor claridad la función de instancia de deliberación crítica y justificación políticoconstitucional que cumple la Corte Constitucional respecto de las decisiones de organización y funcionamiento del servicio público. En ejercicio de su papel, la Corte ha respetado el criterio de eficiencia, competitividad y libertad de empresa por parte de las entidades prestadoras de salud, lo que corresponde a la decisión del constituyente de permitir la prestación del servicio por particulares bajo la dirección, vigilancia y control de las autoridades públicas. A este criterio se suma, no obstante, el criterio del mínimo material indisponible por parte de las entidades reguladoras y prestadoras del servicio. Tal mínimo coincide con el respeto a los principios, derechos y deberes constitucionales. Tanto a las autoridades como a los particulares les está vedado desconocer los principios, derechos y deberes establecidos en la Constitución al desplegar sus competencias y ejercer sus libertades. La Corte Constitucional cumple aquí la tarea de guía normativo del sistema tanto en el plano de su diseño

\footnotetext{
${ }^{37}$ Ver, entre otras, las sentencias T-666 de 1997, T-155 de 2000, T-179 de 2000, T-378 de 2000, T-284 de 2001.
} 
y funcionamiento -como ocurre, ejemplo, con el respaldo a las decisiones de los médicos tratantes de autorizar tratamientos y medicamentos no incluidos en el POS-, o en el plano de su vigilancia y control.

III. CONTEXTOS EMPÍRICO Y NOTAS DE DERECHO COMPARADO

El siguiente apartado tiene el propósito de suministrar alguna información y hacer un breve análisis sobre algunos aspectos relacionados con el derecho a la salud y la justicia constitucional. Para ello se aborda la escasa estadística disponible (1) y se hace una breve alusión al derecho comparado en relación con la garantía del derecho a la salud (2).

\section{Estadística de la jurisprudencia}

La estadística de acciones de tutela y fallos de constitucionalidad y de tutela es totalmente deficiente en el país. ${ }^{38}$ Los datos que a continuación se mencionan y sirven de base para realizar algunas observaciones fueron obtenidos mediante la dispendiosa labor de búsqueda manual o mecánica de la información. Ello explica que sólo sean parciales e incompletos.

El doctor Oscar Dueñas, magistrado auxiliar de la Corte Constitucional, afirma basado en información de esta corporación que desde 1992 hasta el 31 de enero de 2004, llegaron a la Corte Constitucional colombiana, para su eventual revisión, 850.569 expedientes de tutela. ${ }^{39}$ La utilización de este mecanismo de protección ha ido en aumento año tras año. Mientras que en 1992 se recibieron en la Corte 10.732 expedientes de tutela, en 1995 fueron 29.950, en 1998 fueron 38.248 y en 2001 el número ascendió a 133 mil expedientes. Según el mismo doctor Dueñas para 1999 el $23 \%$ de los casos se relacionaban con salud. ${ }^{40}$ Por su parte, el doctor Aquiles Arrieta trae en su escrito sobre la jurisprudencia constitucional en materia de salud los siguientes datos: "En 1999 de las 86.324 tutelas interpuestas en todo el país, ${ }^{41}$ el 24.6\% (21.313) fueron de salud. En el año 2000 el número de tutela aumentó a 131.765 y el 18.9\% (24.913) fueron de salud. En el año 2001 el número de tutelas aumentó muy poco, 133.273, pero el porcentaje de tutelas en salud sí aumentó, pues pasó a ser el 25.6\% (34.226). En el año 2002 la tendencia continuó, incrementando levemente. Para el 1 de diciembre de 2002 se habían presentado 140.095 tutelas de las cuales tan el 25.03\% (35.072) eran de salud ${ }^{42, " ~(A r r i e t a ~ 2002, ~ 23) . ~}$

\footnotetext{
${ }^{38} \mathrm{Ni}$ siquiera la Corte Constitucional cuenta con información estadística al respecto. Es urgente tomar medidas en este campo, ya que se desperdicia importante conocimiento sobre la marcha institucional y valiosos datos para la evaluación de las políticas públicas, no sólo en el campo de la salud sino en general de todos los servicios públicos. Las acciones de tutela y de constitucionalidad, y las respectivas decisiones (en el caso de la tutela, las decisiones de todos los jueces del país) podrían ser una base confiable para diagnosticar problemas y encontrar soluciones.

39 Oscar Dueñas, "El principio de solidaridad en el pensamiento de los pueblos andinos". Ponencia presentada al XIII Congreso Iberoamericano de Seguridad Social en Salvador de Bahía entre el 23 y 26 de marzo de 2004 (publicada por la Universidad Autónoma de Colombia, págs. 14 y 15).

${ }^{40}$ Ibidem.

${ }^{41}$ Los datos que aquí se presentan fueron suministrados por el departamento de sistemas de la Corte Constitucional.

${ }^{42} \mathrm{Al}$ finalizar el año el consolidado fue el siguiente: se presentaron un total de 143.888 tutelas en todo el país de las cuales 42.756 fueron de salud, es decir el $29,7 \%$.
} 
Una corta investigación de campo ${ }^{43}$ permitió verificar los siguientes datos en relación con las sentencias de tutela proferidas por la Corte Constitucional en sede de revisión: en 1994, de un total de 582 sentencias proferidas, 360 (61.9\%) correspondieron a sentencias de tutela, de las cuales 21 (5.8 \%) versan sobre el derecho a la salud, siendo concedidas 13 tutelas (61.9\%) y denegadas 8 (38.1\%) de ellas. Para 1998 el total de sentencias proferidas por la Corte fue de 805, de las cuales 565 fueron de tutela (70.2\%), 79 (14\%) de las cuales se relacionan con el derecho a la salud, habiendo sido concedidas total o parcialmente 66 (87.4\%) y denegadas 13 (12.6\%) de ellas. En 2003 la Corte se pronunció en 1206 oportunidades, de las cuales 868 (72\%) fueron sentencia de tutela, y de éstas 290 (33.4\%) se refirieron al derecho a la salud, habiendo sido concedidas total o parcialmente 194 (66.9\%) y denegadas 95 (32.8\%). Como se puede observar, tanto el número de decisiones de tutela como el porcentaje de las referidas a la salud, ha venido en aumento a lo largo de los años. ${ }^{44}$

\section{Derecho comparado}

No es aquí el lugar ni la ocasión para hacer un estudio extenso de derecho comparado sobre el derecho a la salud en diferentes ordenamientos jurídicos. Debemos resignarnos a la presentación de algunos lineamientos que sirven para la comprensión del papel que juega la justicia constitucional en la realización de este derecho a nivel internacional.

En países desarrollados que han adoptado la estructura político-jurídica del Estado constitucional, social y democrático de derecho - por ejemplo los países de Europa central - los derechos sociales como la salud se encuentran asegurados para toda la población a nivel legislativo. Tal es el caso de Alemania, Francia, España o Italia, por mencionar sólo algunos donde encontramos una infraestructura administrativa y jurisdiccional especializada para asegurar la vigencia de las funciones sociales del Estado, como por ejemplo, la protección de la asistencia médica a toda la población, bien sea mediante su prestación por parte del Estado (como en Inglaterra), o por el Estado con la colaboración de los particulares (como en Alemania o España); lo importante es que la universalidad del acceso a la salud está garantizada. En estas sociedades "bien ordenadas", en los términos de John Rawls, la jurisdicción constitucional, por regla general, no interviene para asegurar el goce efectivo del derecho a la salud, puesto que existe una jurisdicción especializada para la aplicación de la ley: la jurisdicción social. Los Tribunales constitucionales de estas sociedades sólo cumplen una función que podríamos llamar de control, en el sentido de que sólo intervienen en casos excepcionales, cuando se intenta el

\footnotetext{
${ }^{43}$ Agradezco a este respecto a mi asistente de investigación Paula Torres Holguín.

${ }^{44}$ No se incluyen aquí los derechos al medio ambiente sano o a la salubridad, que son vistos como derechos colectivos, salvo afectación directa de derechos fundamentales individuales. En informe especial de Ámbito Jurídico, Legis AñoVI - No. 135, Bogotá, 18 al 31 de agosto de 2003, pág. 2B se recoge una estadística según la cual entre los años 1992 y 2001, el número de tutelas revisadas por la Corte fue de 5671 (68.16\%). De estas, un total de 3312 (58.4\%) fueron concedidas y 2359 (41.6\%) fueron negadas. El año de mayor número de tutelas revisadas fue el 2000, con 1340. De estas 820 (61.19\%) fueron concedidas y 520 (38.8\%) negadas. El de mayor número de tutelas negadas fue 1992, con el 53.2\%, y el de tutelas concedidas fue 1999 con $69.21 \%$.
} 
desmonte de la legislación social por debajo de los mínimos compatibles con la dignidad humana.

En contraste, en países en vía de desarrollo no existe, o existe de manera precaria, una infraestructura administrativa y de control, una legislación y una jurisdicción sociales en las que se realice el Estado social de derecho. La pobreza, la desigualdad y la exclusión, unidas a la carencia de recursos económicos por parte del Estado, la corrupción de autoridades y particulares y las precisiones de intereses supranacionales, son una constante que favorece la vulneración de los principios, derechos y deberes más fundamentales de la persona. En esta realidad de los "países no bien ordenados", 45 el reconocimiento a nivel constitucional del derecho fundamental a la salud, ya sea por decisión constituyente (Brasil en $1988^{46}$ o Colombia en 1991 respecto de los menores de $\operatorname{edad}^{47}$ ), o sea por interpretación de los tribunales constitucionales como en el caso colombiano o el sudafricano, ${ }^{48}$ deja entrever la creciente conciencia sobre la necesidad de asegurar, como mínimo, la dignidad humana a toda la población, mediante la realización de los derechos sociales fundamentales. ${ }^{49}$ Naturalmente a esta pretensión se oponen sectores y personas sobre las que recae directa o indirectamente la redistribución económica implícita en la garantía constitucional del derecho a la salud, pese a las claras decisiones constituyente, legislativa y jurisprudencial.

Si bien a la Corte Constitucional colombiana se le critica una excesiva injerencia en este tipo de problemas, en otros países "no bien ordenados”, con incipiente desarrollo del Estado constitucional, social y democrático de derecho, pertenecientes a diversas tradiciones jurídicas, la intervención de los jueces constitucionales para la garantía de mínimos iusfundamentales es frecuente, y cumple funciones similares. En efecto, en India, Suráfrica, Hungría y otros países del Este, los jueces constitucionales cumplen funciones similares o equivalentes a las desempeñadas por los jueces constitucionales y de tutela en Colombia. Para tomar sólo el ejemplo de Sudáfrica, encontramos que, en este país, los jueces constitucionales han intervenido para proteger la exigibilidad judicial de un mínimo de derechos sociales, económicos y culturales (Sunstein 2001, 11 ss.), entendidos éstos como derechos de desarrollo progresivo, pero que no por ello dejan de ser exigibles judicialmente según el principio de razonabilidad. Así, en el caso Grootboom, la Corte Constitucional surafricana amparó el derecho a una vivienda digna de 900 personas, entre ellas 510 niños, que habitaban un tugurio con

\footnotetext{
${ }^{45}$ En la categoría de "países no bien ordenados” pueden incluirse economías tan dispares como la colombiana, boliviana, brasileña o argentina, pero también buena parte de los países del África o del Este Europeo.

${ }^{46}$ Ingo Wolfgang Sarlet, Algumas considerações em torno do conteúdo, eficácia e efectividade do direito à saúde na Constituição de 1988, en: Revista Diálogo Jurídico Num. 10, Janeiro 2002, Salvador-BahíaBrasil, p. 3.

${ }^{47}$ Artículo 44 de la Constitución.

${ }^{48}$ Cass R. Sunstein. Social and Economic Rights? Lessons from South Africa (May 2001). U of Chicago, Public Law Working Paper No. 12; U Chicago Law \& Economics, Olin Working Paper No. 124; Frank I. Michelman. The constitution, social rights, and liberal political justification International Journal of Constitutional Law Volume 1, Issue 1, January 2003: pp. 13-34.

${ }^{49}$ Cfr. Rodolfo Arango, La justiciabilidad de los derechos sociales fundamentales, Revista de Derecho Público No. 12, Facultad de Derecho, Universidad de los Andes, Bogotá 2001, 185-212.
} 
condiciones de vida deplorables y que habían estado por varios años en una lista de espera para recibir vivienda social. Según la interpretación de la Corte la Constitución no sólo impone el deber de adoptar planes de largo plazo para asegurar vivienda a los sectores de menores ingresos, sino además el deber de procurarles vivienda temporal en condiciones dignas. La Corte concluyó que la ausencia de una plan "razonable” de vivienda temporal para ayudar a personas que no tienen donde vivir, vulneró sus derechos constitucionales.

Víctor Abramovich y Cristian Courtis y mencionan tres casos relevantes en materia de salud en Argentina. El primero es el caso de la Asociación Benghalensis y otros contra el Ministerio de Salud y Acción Social presentado ante la Cámara Nacional en los Contencioso Administrativo Federal, y cuya sentencia fue confirmada por la Corte Suprema de Justicia de la Nación Argentina el 1 de junio de 2000. En dicho fallo se condenó al Estado a "dar cumplimiento a su obligación de asistencia, tratamiento y en especial, suministro de medicamentos en forma regular, oportuna y continua a aquellos enfermos que padecen las consecuencias del virus HIV/SIDA que se encuentran registrados en los hospitales y efectores sanitarios del país”, después de haber reconocido la legitimidad de un grupo de ONG'S encargadas de luchar contra el SIDA para interponer, en nombre de todos los afectados por dicha enfermedad, el recurso de amparo tendiente a la protección de dicho derecho social, que era negado aun cuando existía una norma legal que obligaba a la prestación del servicio médico a los enfermos de SIDA, en los mismos términos en que fue condenado el Estado (Abramovich/Courtis 2002, 139-140).

El segundo caso es el caso conocido como Hospital Leonidas Lucero, en el cual la Cámara Civil y Comercial de Bahía Blanca, Provincia de Buenos Aires, sostuvo que 34 enfermos de SIDA atendidos en dos hospitales diferentes tenían derecho no sólo al suministro inicial, sino a la continuidad del tratamiento con retrovirales para su enfermedad por parte del Estado. De esta forma, el Estado no podía eludir su obligación aduciendo que ya había suministrado inicialmente lo medicamentos (Abramovich/Courtis 2002, 143-144).

Finalmente, en el caso de Maria Cecilia Viceconte contra el Estado Nacional Argentino, la Cámara Nacional de Apelaciones en lo Contencioso Administrativo sostuvo que el Estado tenía la obligación de garantizar la producción y consecuente repartición de una vacuna contra la llamada Fiebre Hemorrágica Argentina, una enfermedad viral de fácil contagio que sólo se presentaba en ese país, y que por ser poco rentable económicamente, los laboratorios privados habían decidido no producir, sin tener en cuenta que la enfermedad era mortal, y que dada su exclusiva locación geográfica, no era producida en alguna otra parte del mundo. Si bien el Estado sostuvo que ya había destinado una partida presupuestal para la vacuna, los jueces comprobaron serios retrasos en los cronogramas de la producción, lo que violaba su obligación de hacer frente a la enfermedad de manera eficaz y oportuna, razón por la cual el Estado fue condenado (Abramovich/Courtis 2002).

En resumen, la intervención de los jueces constitucionales en materia de derechos sociales, incluido el derecho a la salud, es algo generalizado en varios países que han adoptado el modelo de Estado constitucional, democrático y social de derecho. 
En estos países los tribunales constitucionales garantizan la exigibilidad judicial de los derechos sociales mínimos que se deducen del orden constitucional. Los casos de Colombia y Sudáfrica son paradigmáticos en este sentido.

\section{CONCLUSIONES}

1. El derecho a la salud es uno de los mejores termómetros para medir la vigencia del Estado social de derecho. Ello porque si las personas enfermas no tiene la posibilidad de acceder efectivamente a los servicios de asistencia médica no es posible hablar de un Estado social, el cual se caracteriza por garantizar la realización mínima de los derechos sociales, económicos y culturales.

2. El constituyente optó por un modelo político de Estado social de derecho en el que se garantiza el derecho a la salud para toda la población en forma solidaria y eficiente. Tal modelo supone una tensión entre, por una parte, la garantía constitucional del derecho a la salud y, por otra, el carácter progresivo de este derecho y su necesario desarrollo legal.

3. La justicia constitucional, en particular la Corte Constitucional, en una profusa jurisprudencia, ha resuelto la tensión entre la salud como derecho y como servicio público de desarrollo legal, mediante la teoría del derecho fundamental a la salud por conexidad. Según esta teoría, la salud es y debe recibir la protección especial de un derecho fundamental cuando, de no hacerlo, se ponen en riesgo otros derechos fundamentales como la vida, la integridad personal o la libertad.

4. La intervención de la justicia constitucional en materia del derecho a la salud se manifiesta en por lo menos cinco ámbitos: la definición del derecho; sus beneficiarios; su alcance; el acceso y la calidad al servicio. Tal intervención ha tenido lugar en dos niveles: individual, mediante la protección inmediata del derecho fundamental a la salud en casos concretos; y, general, mediante el control constitucional al diseño, organización y funcionamiento del sistema general de seguridad social en salud.

5. En ejercicio de la intervención de los jueces de tutela y la Corte Constitucional en los distintos ámbitos de la salud, los jueces constitucionales cumplen claras y precisas funciones: (i) de definición del derecho fundamental a la salud y sus obligaciones correlativas; (ii) de protección especial a personas o grupos en situación de marginación o discriminación; (iii) de delimitación y coordinación de los niveles constitucional y legal; (iv) de control constitucional a la formulación y ejecución de las políticas públicas en cuanto puedan afectar derechos fundamentales; (v) de integración e inclusión social mediante el respeto a los principios, derecho y deberes constitucionales; (vi) de legitimación jurídico política del ordenamiento jurídico; (vii) de interlocución con las instancias reguladoras encargadas del control y vigilancia de los servicios públicos.

6. Una apreciación global del número de sentencias proferidas por la Corte Constitucional y los jueces de tutela del país muestra un aumento tanto del número de acciones de tutela y de sentencias de revisión relativas al derecho a la salud. Si en el año 1994 representaban estás últimas el 5.8\% del total de sentencias de la Corte, en 1998 era ya el 14\% y en 2003 el 33.4\%. Las tutelas concedidas por la Corte oscilan entre el 60 y el $70 \%$. En su tarea de sentar reglas jurisprudenciales claras la Corte 
contribuye a que los derechos sociales, económicos y culturales se realicen efectivamente de manera progresiva.

7. La población aún no cubierta por el sistema de salud oscila entre el 43 y el $47 \%$ de la población, según diversos estudios. Pese al aumento importante del cubrimiento en la última década, actualmente entre 19 y 21 millones de personas no tienen garantizado su acceso al sistema de salud mediante el régimen contributivo ni el subsidiado.

8. Los problemas de acceso y calidad del servicio prestado por EPS y ARS, públicas o privadas, han aumentado, como lo demuestra el aumento de demandas de tutela. La solución a esta problemática no parece radicar en prohibir la acción de tutela en relación con los derechos sociales, entre ellos el de salud.

9. Por el contrario, las actuaciones de la justicia constitucional en el campo de la salud ofrecen un diagnóstico cualitativo de los retos que enfrenta la sociedad y las instituciones políticas colombianas para la realización efectiva del Estado social de derecho. Tales retos tiene que ver con el respeto a la vida, la integridad y la dignidad humanas, como cuando la justicia constitucional ha intervenido para evitar que la dilación injustificada de la prestación del servicio ocasione un perjuicio irremediable a la persona.

10. La posibilidad de acudir a la acción de tutela para evitar la vulneración del derecho fundamental a la salud por conexidad con otros derechos fundamentales, ha permitido brindar protección especial a grupos discriminados o marginados y a personas que se encuentran en situación de debilidad manifiesta, entre ellos a menores de edad; personas con pronóstico no favorable de curación; mujeres embarazadas o luego del parto; las minorías étnicas; adultos mayores; personas con discapacidad; enfermos de SIDA; personas privadas de la libertad; personas víctimas de desplazamiento forzoso; o, personas en situación de indigencia.

11. La jurisprudencia constitucional ha servido igualmente para fijar el alcance del derecho fundamental a la salud por conexidad, mediante la delimitación de las obligaciones correlativas y sus titulares. Las sentencias de revisión subrayan la corresponsabilidad que existe entre el titular del derecho, su familia, las entidades prestadoras del servicio, el patrono en caso de asalariados y el Estado, para garantizar el goce efectivo del derecho a la salud. Ello porque la indefinición o falta de certeza sobre el alcance de los derechos y obligaciones de los actores sociales favorece su desconocimiento, lesiona los principios de reciprocidad, solidaridad y dignidad humana, y fractura el orden social.

12. La Corte Constitucional como instancia de reflexión jurídico político ha servido como árbitro en la distribución de los beneficios y cargas del sistema de salud en caso de conflicto. También se ha ocupado de evaluar la razonabilidad y proporcionalidad del diseño y funcionamiento del sistema de salud para garantizar el acceso de todos al mismo y su calidad.

13. La intervención de la justicia constitucional en el ámbito del derecho a la salud muestra la necesidad de un desarrollo legal que aborde la complejidad del tema. La creación de una legislación social y de una jurisdicción social de tutela son 
prioridades legislativas que en un periodo de ampliación y consolidación del Estado constitucional, democrático y social de derecho. La jurisprudencia constitucional sobre la materia constituye un invaluable material de diagnóstico y análisis en este campo. La justicia constitucional debe seguir cumpliendo las funciones que ha venido cumpliendo en materia del derecho a la salud mientras no sea sustituida por una justicia especializada que asegure el mismo o mayor nivel de eficacia en la protección de este derecho constitucional.

14. La estadística de la jurisprudencia constitucional en salud requiere de mayor desarrollo. Puede ser un importante indicador del funcionamiento de los servicios públicos y, en general, de la marcha de las instituciones encargadas de su prestación. Se requiere de una estadística más detallada que permita apreciar las situaciones de vulneración o amenaza de los derechos, los potenciales o reales infractores, las conductas generales contrarias a los derechos, las órdenes impartidas por los jueces constitucionales, el costo de las decisiones judiciales, los vacíos jurídicos existentes, etc.

15. La experiencia de derecho comparado muestra que Colombia no es un caso aislado en relación con la constitucionalización del derecho ordinario y la intervención de la justicia constitucional en materia de protección de los derechos de prestación. La salud, además, es un derecho constitucional y un objetivo público que trasciende los marcos del contrato privado entre beneficiario y entidad aseguradora. Los países desarrollados que han adoptado el modelo político del Estado constitucional, democrático y social de derecho, cuentan con una legislación, estructura administrativa y sistema judicial especializado en lo social. En ellos, por lo general, no se requiere la intervención constitucional en materia de salud. Por el contrario, en los países del tercer mundo dicha intervención cumple importantes funciones para proteger contenidos constitucionales esenciales, fortalecer la legitimidad del Estado, mediante la ampliación y consolidación de la institucionalidad necesaria para garantizar a todos los habitantes, e incluir a las personas y sectores marginados o discriminados por la lógica del mercado.

16. La presente investigación muestra la importancia que ha adquirido la acción de tutela para la protección del derecho a la salud, en particular de los sectores más débiles de la población. También disipa la idea de que la jurisdicción constitucional atenta contra la estabilidad del sistema de seguridad social en salud; por el contrario, son los jueces constitucionales quienes han permitido que lentamente se vaya construyendo una dogmática seria y bien fundamentada de los titulares, el contenido de las prestaciones y el reparto de las cargas implícitas en la realización del derecho a la salud. No es recortando la acción de tutela y las facultades de la justicia constitucional que se logra la construcción del Estado social de derecho.

\section{BIBLIOGRAFÍA}

ABRAMOVICH, Víctor; COURTIS, Cristian. Los derechos sociales como derechos exigibles, Trotta, Madrid, 2002.

ARRIETA, Aquiles. Comentarios a la creación de jurisprudencia constitucional. El caso del acceso a los servicios de salud, Bogotá 2002 (Manuscrito).

ARANGO, Rodolfo; LEMAITRE, Julieta. Jurisprudencia constitucional sobre el derecho al mínimo vital, Revista Estudios Ocasionales, Centro de Investigaciones Socio-Jurídicas (CIJUS), Facultad de Derecho, Universidad de los Andes, Bogotá, 2002. 
ARANGO, Rodolfo. Promoción de los derechos sociales constitucionales por vía de protección judicial, en: Otras miradas de la justicia. El Otro Derecho No. 28, ISLA, Bogotá, 2002, pp. 103-122.

ARANGO, Rodolfo. La justiciabilidad de los derechos sociales fundamentales, Revista de Derecho Público No. 12, Facultad de Derecho, Universidad de los Andes, Bogotá, 2001, pp. 185-212.

ARANGO, Rodolfo. Los derechos sociales fundamentales como derechos subjetivos, Pensamiento Jurídico No. 8, Facultad de Derecho y Ciencias Políticas, Universidad Nacional, 1997, pp. 63-72.

ARBELÁEZ RUDAS, Mónica. La protección del derecho a la salud en sede de tutela. Consideraciones doctrinarias y líneas jurisprudenciales de la Corte Constitucional. Trabajo presentado como monografía a la Especialización en Derecho Constitucional de la Facultad de Derecho, Ciencias Políticas y Sociales, Universidad Nacional de Colombia, Bogotá, 2000.

BELALCAZAR, Isabel. Derecho a la salud, dignidad humana y solidaridad. Trabajo presentado como monografía a la Especialización en Derecho Constitucional de la Facultad de Derecho, Ciencias Políticas y Sociales, Universidad Nacional de Colombia, Bogotá, 2002.

PARRA VERA, Óscar. Defensoría del Pueblo. El derecho a la salud en la Constitución, la jurisprudencia y los instrumentos internacionales. Serie Desc, Bogotá, 2002.

DUEÑAS, Oscar. El principio de solidaridad en el pensamiento de los pueblos andinos. Ponencia presentada al XIII Congreso Iberoamericano de Seguridad Social en Salvador de Bahía entre el 23 y 26 de marzo de 2004 (publicada por la Universidad Autónoma de Colombia, págs. 14 y 15).

GARCÍA VILLEGAS, Mauricio; UPRIMNY YÉPES, Rodrigo. La reforma a la tutela: ¿ajuste o desmonte?, Revista de Derecho Público, No. 15, Facultad de derecho, Universidad de los Andes, Bogotá, 2002, pp. 245-286.

MICHELMAN, Frank I. The constitution, social rights, and liberal political justification, International Journal of Constitutional Law Volume 1, Issue 1, 2003, pp. 13-34.

RUGGERI, Antonio. The Principle of Reasonableness and the Distinctiveness of Constitutional Interpretation, en: Ars Interpretandi, Yearbook of Legal Hermeneutics 7, 2002, pp. 239-298.

RESTREPO ZEA, Jairo. El seguro de salud en Colombia ¿Cobertura universal?, Revista Gerencia y Políticas de Salud No. 2, 2002.

SARLET, Ingo Wolfgang. Algumas considerações em torno do conteúdo, eficácia e efectividade do direito à saúde na Constituição de 1988, en: Revista Diálogo Jurídico Num. 10, SalvadorBahía-Brasil, 2002.

SUNSTEIN, Cass R. Social and Economic Rights? Lessons from South Africa. U of Chicago, Public Law Working Paper No. 12; U Chicago Law \& Economics, Olin Working Paper No. 124. 2001.

UPRIMNY, Rodrigo; RODRÍGUEZ, César; GARCÍA-VILLEGAS, Mauricio. Entre el protagonismo y la rutina: Análisis sociojurídico de la justicia en Colombia, en: Culturas Jurídicas Latinas de Europa y América en tiempos de globalización, Fix-Fierro, Héctor/ Friedman, Lawrence/ Pérez Perdomo, Rogelio (eds), Universidad Autónoma de México, México, 2003, pp. 231-305. 